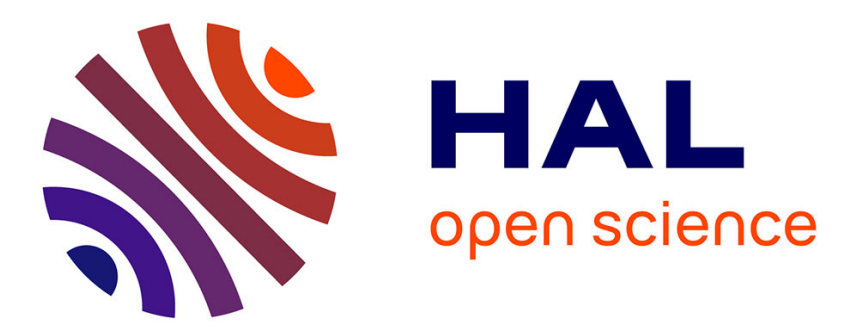

\title{
Arabinose Conjugates Diagnostic of Ferulate-Ferulate and Ferulate-Monolignol Cross-Coupling Are Released by Mild Acidolysis of Grass Cell Walls
}

\author{
Catherine Lapierre, Aline Voxeur, Stéphanie Boutet, John Ralph
}

\section{- To cite this version:}

Catherine Lapierre, Aline Voxeur, Stéphanie Boutet, John Ralph. Arabinose Conjugates Diagnostic of Ferulate-Ferulate and Ferulate-Monolignol Cross-Coupling Are Released by Mild Acidolysis of Grass Cell Walls. Journal of Agricultural and Food Chemistry, 2019, 67, pp.12962 - 12971. 10.1021/acs.jafc.9b05840 . hal-03080299

HAL Id: hal-03080299

https://hal-agroparistech.archives-ouvertes.fr/hal-03080299

Submitted on 17 Dec 2020

HAL is a multi-disciplinary open access archive for the deposit and dissemination of scientific research documents, whether they are published or not. The documents may come from teaching and research institutions in France or abroad, or from public or private research centers.
L'archive ouverte pluridisciplinaire HAL, est destinée au dépôt et à la diffusion de documents scientifiques de niveau recherche, publiés ou non, émanant des établissements d'enseignement et de recherche français ou étrangers, des laboratoires publics ou privés. 


\title{
Arabinose Conjugates Diagnostic of Ferulate-Ferulate and Ferulate- Monolignol Cross-Coupling Are Released by Mild Acidolysis of Grass Cell Walls
}

\author{
Catherine Lapierre, ${ }^{*}{ }^{\dagger}$ Aline Voxeur, ${ }^{\dagger}$ Stéphanie Boutet, ${ }^{\dagger}$ and John Ralph ${ }^{\ddagger}$. \\ ${ }^{\dagger}$ Institut Jean-Pierre Bourgin, INRA, AgroParisTech, CNRS, Université Paris-Saclay, Versailles 75231, France \\ ${ }^{\ddagger}$ Department of Biochemistry, and The Department of Energy's Great Lakes Bioenergy Research Center, The Wisconsin Energy \\ Institute, University of Wisconsin, Madison, Wisconsin 53726, United States
}

\section{Supporting Information}

ABSTRACT: Ferulate (FA) units esterified to grass arabinoxylans are involved in cross-linking cell wall polymers. In this work, this contention is strengthened by the identification of FA homo- and heterodimers esterified to methyl arabinofuranoside (MeAra) units after their release from the xylan by mild acidolysis in dioxane/methanol/HCl. Acidolysis of poorly lignified maize bran cell walls provided diferulate (DFA) isomers, including those from $8-5,8-O-4$, and 5-5 interunit bonding, esterified to one or two MeAra units. Acidolysis of lignified grass samples released crossed dimers esterified to one MeAra unit and derived from the $\beta-O-4$ coupling of coniferyl alcohol to FA esters. The evaluation of these heterodimeric esters by LC-UV of their aglycones revealed that the parent structures occur in significant amounts in lignified cell walls $(0.5-1 \mathrm{mg} / \mathrm{g}$ expressed as FA equivalents). The present results position mild acidolysis as an efficient strategy to obtain improved details regarding the FA-mediated cross-linking of grass cell walls.

KEYWORDS: radical coupling, dehydrodimer, lignification, cell wall cross-link, diferulate, monocot

\section{INTRODUCTION}

Commelinid monocot ferulate (FA) units that are ester-linked to arabinoxylans (AX) may act as cross-links between $\mathrm{AX}$ chains or between AX and lignins. ${ }^{1-5}$ Due to the crucial role of feruloylated arabinosyl units in grass cell wall strengthening, we recently developed a method to evaluate the relative acylation of arabinose units by ferulate vs $p$-coumarate ( $p$ CA). ${ }^{6}$ Mild acidolysis in a dioxane/methanol/aqueous $2 \mathrm{M} \mathrm{HCl}$ mixture provided methyl 5-O-feruloyl arabinofuranose (FA-MeAra) and methyl 5-O-p-coumaroyl arabinofuranose ( $p$ CA-MeAra) that could be readily analyzed by LC-MS or LC-UV. When it was applied to (monocot family) grass cell walls, this method revealed that the acylation of arabinoxylans by $\mathrm{FA}$ or $p \mathrm{CA}$ displayed a marked spatiotemporal variability. In this work, we establish that mild acidolysis of lignified grass cell walls releases various similarly esterified dehydrodiferulates as well as new arabinose conjugates diagnostic of the oxidative $(\beta-O-4)$ cross-coupling of monolignols to arabinoxylan-linked FA esters.

\section{MATERIALS AND METHODS}

Chemicals. ACS grade dioxane, methanol, acetonitrile, and ethyl acetate solvents were obtained from Carlo Erba Reagents (Val de Rueil, France). Aqueous $2 \mathrm{M} \mathrm{HCl}$ standard solution and $\mathrm{N}, \mathrm{O}$ bis(trimethylsilyl)trifluoroacetamide (BSTFA) were purchased from Aldrich (St Quentin, France).

Plant Materials. Miscanthus lower internodes, stems, or leaves (M. sinensis and M. x giganteus) were harvested in the field (February harvest). Maize stems (F2 INRA line) were harvested at silage stage and in the field. All samples were dried, ground to $<0.5 \mathrm{~mm}$, and then subjected to exhaustive extraction with water and ethanol in a Soxhlet apparatus. An alcohol-insoluble residue was obtained from a commercially available maize bran sample (from ULICE, Riom, France) according to a published method. ${ }^{7}$ All of these extracted samples, referred to as extract-free samples in the following, were oven-dried at $50{ }^{\circ} \mathrm{C}$ before mild acidolysis.

Mild and Severe Alkaline Hydrolyses of Grass Cell Walls. FA units linked to grass cell walls by only ester linkages were released from $10 \mathrm{mg}$ extract-free samples subjected to mild alkaline hydrolysis ( $1 \mathrm{~mL}$ aqueous $1 \mathrm{M} \mathrm{NaOH}$, overnight at room temperature). FA units linked to grass cell walls by both ester and ether linkages were released by severe alkaline hydrolysis as follows. About $10 \mathrm{mg}$ of an extract-free sample was introduced together with $2 \mathrm{~mL}$ of aqueous 4 $\mathrm{M} \mathrm{NaOH}$ into a Teflon screw-cap vial. This vial was then put into a stainless steel reaction vessel at $170{ }^{\circ} \mathrm{C}$ (oven) for $2 \mathrm{~h}$. The cooled reaction mixtures recovered from mild or severe alkaline hydrolyses were acidified to $\mathrm{pH} 2-3$ (aqueous $6 \mathrm{M} \mathrm{HCl}$ ) and then purified by solid-phase extraction before HPLC analysis according to a published method. ${ }^{8}$

Mild Acidolysis of Grass Cell Walls. The acidolysis reagent was prepared just before use by mixing dioxane, methanol, and aqueous 2 $\mathrm{M} \mathrm{HCl}(60 / 30 / 10, \mathrm{v} / \mathrm{v} / \mathrm{v})$. About $10 \mathrm{mg}$ of an extract-free sample was introduced with $1 \mathrm{~mL}$ of acidolysis reagent into a $4 \mathrm{~mL}$ vial equipped with a Teflon-lined cap. The vials were then incubated for 3 $\mathrm{h}$ at $80{ }^{\circ} \mathrm{C}$ with agitation at $500 \mathrm{rpm}$ (Bioer thermomixer, Dutscher, Brumath, France). The cooled reaction mixture was diluted with about $2 \mathrm{~mL}$ of water, and the diluted mixture was then subjected to extraction with ethyl acetate $(3 \times 3 \mathrm{~mL})$. The organic extracts were combined, dried over anhydrous sodium sulfate, and evaporated on a rotary evaporator. The acidolysis-derived compounds were redissolved in about $1 \mathrm{~mL}$ of $\mathrm{CH}_{3} \mathrm{CN}$ before ultrafiltration (Chromafil Xtra

Received: September 16, 2019

Revised: October 21, 2019

Accepted: October 23, 2019

Published: October 23, 2019 

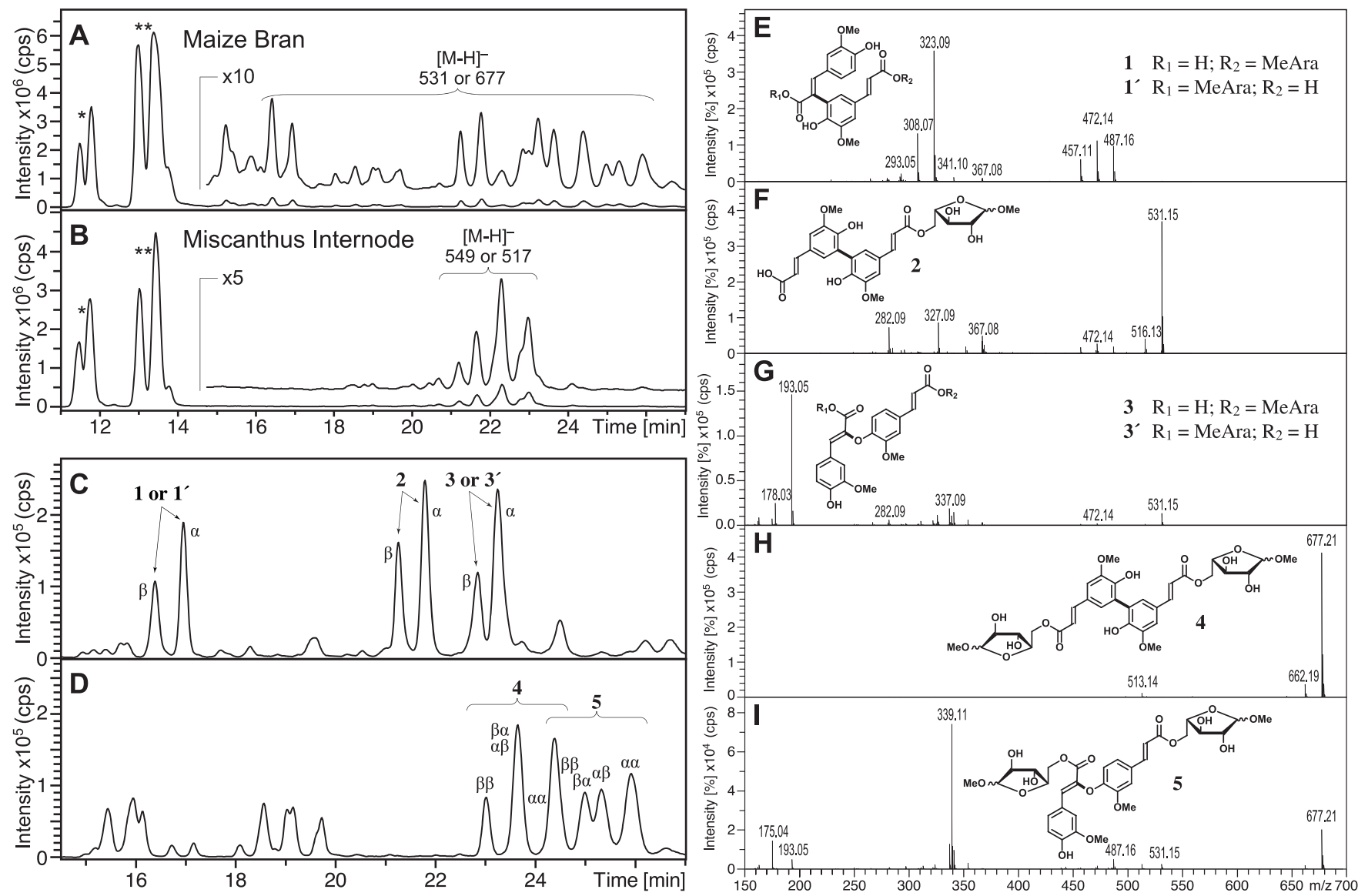

phenolics recovered after mild acidolysis of extract-free maize bran Figure 1. LC-MS analyses (ESI negative mode) of the low-molecular-weight phenolics recovered after mild acidolysis of extract-free maize bran
sample (A, C, and D traces) and of miscanthus lignified internode (M. sinensis) (B trace). Total ion chromatograms are shown in (A) and (B); expanded chromatograms reconstructed at $m / z 531$ and 677 and normalized to the same intensity scale are shown in (C) and (D), respectively. The major peak pairs eluted before 14 min correspond to $p$ CA-MeAra $(*)$ and FA-MeAra $(* *)$, respectively $(\beta$ and $\alpha$ anomers, in that order). The $\mathrm{MS}^{2}$ spectra of isomers associated with peak pairs 1-3 are shown in (E)-(G) (ion $\mathrm{m} / z 531.151$ fragmented at a collision energy (CE) of $35.9 \mathrm{eV}$ ), whereas those of isomers from peak clusters $\mathbf{4}$ and $\mathbf{5}$ are shown in (H) and (I) (ion $m / z 677.209$ fragmented at CE $40.3 \mathrm{eV}$ ), respectively, together with the corresponding structures. Vertical axis scales are in cps (counts per second).

$0.45 \mu \mathrm{m}$ filter disk, Macherey-Nagel, Hoerdt, France) and then HPLC analysis.

Alkaline Hydrolysis of Acidolysis Mixtures. A fraction of the acidolysis solution (about $0.5 \mathrm{~mL}$ ) was redissolved in about $2 \mathrm{~mL}$ of aqueous $1 \mathrm{M} \mathrm{NaOH}$, and mild alkaline hydrolysis was carried out overnight at room temperature. After acidification with $0.2 \mathrm{~mL}$ of aqueous $6 \mathrm{M} \mathrm{HCl}$, the reaction mixture was extracted with ethyl acetate $(3 \times 3 \mathrm{~mL})$. The organic extracts were combined, dried over anhydrous sodium sulfate, and evaporated on a rotary evaporator. The low-molecular-weight phenolics were redissolved in $\mathrm{CH}_{3} \mathrm{CN}$ before chromatographic analysis.

LC-UV and LC-MS Analyses. LC-UV and LC-MS analyses were performed by injecting $1 \mu \mathrm{L}$ of sample onto an RP18 column as previously described. ${ }^{6}$ The LC-UV quantitative evaluation of the ferulate heterodimers released after alkaline hydrolysis of the acidolysis mixture was made using the response factor of ferulic acid. For LC-MS analysis, we used an HPLC system (UltiMate 3000 RS HPLC system, Thermo Scientific, Waltham, MA, USA) coupled to an Impact II Ultra-High Resolution Qq-Time-Of-Flight (UHR-QqTOF) spectrometer (Bruker Daltonics, Bremen, Germany) equipped with an electrospray ionization (ESI) source. MS detection was performed in the negative ion mode with spectra acquired over the $100-1000 \mathrm{~m} / z$ range. The instrument settings were as follows: capillary voltage, $+2.5 \mathrm{kV}$; nebulizing gas $\left(\mathrm{N}_{2}\right)$ pressure, 3.4 bar; temperature, $200{ }^{\circ} \mathrm{C}$; drying gas $\left(\mathrm{N}_{2}\right)$ flow, $10 \mathrm{~L} / \mathrm{min}$. Additional ESI $\mathrm{MS}^{2}$ experiments were performed in the auto MS-MS negative ion mode with the collision energy (CE) varying between 35 and $40.3 \mathrm{eV}$.
GC-MS Analyses. The identity of the low-molecular-weight phenolics released from grass cell walls by acidolysis followed by alkaline hydrolysis was established by GC-MS of their trimethylsilylated (TMS) derivatives. An $\sim 10 \mu \mathrm{L}$ aliquot of the $\mathrm{CH}_{3} \mathrm{CN}$ solution was trimethylsilylated with $100 \mu \mathrm{L}$ of BSTFA and $10 \mu \mathrm{L}$ of GC-grade pyridine, for $1 \mathrm{~h}$ at $50{ }^{\circ} \mathrm{C}$. The TMS solution was injected $(1 \mu \mathrm{L})$ into a GC-MS Varian 4000 instrument (Varian, Les Ulis, France) fitted with an Agilent combiPAL autosampler, a splitless injector $\left(280^{\circ} \mathrm{C}\right)$, and an ion-trap mass spectrometer (electron impact mode, $70 \mathrm{eV}$ ), with a source at $220{ }^{\circ} \mathrm{C}$, a transfer line at $280{ }^{\circ} \mathrm{C}$, and an $\mathrm{m} / z$ 50-800 scanning range. The GC column was a Restek Rxi-5SilMS (30 m $\times$ $0.25 \mathrm{~mm}$ i.d., Interchim, Montluçon, France) working in the temperature program mode from 45 to $110{ }^{\circ} \mathrm{C}$ at $+30{ }^{\circ} \mathrm{C} / \mathrm{min}$ and then 110 to $330{ }^{\circ} \mathrm{C}$ ramped at $10{ }^{\circ} \mathrm{C} / \mathrm{min}$, with helium as the carrier gas at a $1 \mathrm{~mL} / \mathrm{min}$ flow rate.

\section{RESULTS AND DISCUSSION}

We subjected grass cell walls with contrasting lignin contents to the recently developed mild acidolysis procedure performed in dioxane/methanol/aqueous $2 \mathrm{M} \mathrm{HCl}$; an extract-free sample from maize bran had a lignin content of $<2 \%$, as estimated from the thioacidolysis yield, ${ }^{9}$ and that from miscanthus or maize lignified stem samples had Klason lignin contents in the $17-23 \%$ range. The LC-MS analysis of the phenolics released by acidolysis of the poorly lignified maize bran sample is displayed in Figure 1A and that from a highly 
lignified miscanthus sample in Figure 1B. On both traces, the major peaks, deliberately overloaded here to provide good signals for the more minor components, were those (marked with asterisks) from $p$ CA-MeAra and FA-MeAra, each as pairs of anomers. In addition, smaller peaks could be observed, which differed between the two LC-MS traces. The maize bran chromatogram (Figure 1A) displayed a series of ill-resolved and weak peaks, with $[\mathrm{M}-\mathrm{H}]^{-}$ions at $\mathrm{m} / z 531$ or 677 . On the miscanthus trace (Figure 1B), a substantial peak cluster corresponding to compounds with $[\mathrm{M}-\mathrm{H}]^{-}$ions at $\mathrm{m} / z$ 549 or 517 could be seen. These peaks, which seemed to discriminate the grass samples according to their lignin level, were subjected to more comprehensive mass spectral analyses so as to identify the corresponding structures.

Release by Mild Acidolysis of DFA Isomers Esterified to One or Two Sugar Units from Maize Bran Cell Walls. The small peaks with $m / z 531$ and $677[\mathrm{M}-\mathrm{H}]^{-}$ions from the maize bran trace (Figure 1A) are more precisely observed on extracted-ion chromatograms (Figures 1C,D). These peaks were associated with compounds with $\mathrm{m} / z \quad 531.151$ $\left(\mathrm{C}_{26} \mathrm{H}_{27} \mathrm{O}_{12}{ }^{-}\right)$and $677.208\left(\mathrm{C}_{32} \mathrm{H}_{37} \mathrm{O}_{16}{ }^{-}\right)$accurate masses. From their $\mathrm{MS}^{2}$ analyses and their $m / z 146$ mass difference (MeAra unit, $\mathrm{C}_{6} \mathrm{H}_{10} \mathrm{O}_{6}$ ), we hypothesized that they might correspond to two families of DFA isomers esterified with one or two MeAra units, as explained in the following.

The LC-MS trace reconstructed at $\mathrm{m} / z 531$ displayed three peak pairs labeled 1-3 (Figure 1C) which, following analysis, correspond to assigned structures with the same numbering. As the two components of each peak pair had very similar $\mathrm{MS}^{2}$ spectra, they most likely are the $\beta$ - and $\alpha$-anomers of 1 -Omethyl-arabinosylated diferulates, the ferulate moiety acylating $0-5$, as it invariably does. ${ }^{10-12}$ For each anomeric pair, the predominant $\alpha$ anomer was eluted after the $\beta$ anomer, as reported for FA-MeAra analyzed by reverse-phase HPLC. ${ }^{6}$ The three DFA monoesters were recognized from $\mathrm{MS}^{2}$ analyses (Figures 1E-G), in comparison to published spectra of the parent diferulate aglycones. ${ }^{13-16}$ The $\mathrm{MS}^{2}$ spectra of the two anomers associated with peak pair 3 displayed an intense deprotonated FA ion at $\mathrm{m} / z 193$ (Figure $1 \mathrm{G}$ ), which reveals that they comprise two FA units linked by an interunit bond easily cleaved by mass fragmentation. On this basis, we suggest that they are the $\beta$ - and $\alpha$-anomers of FA- $(8-O-4)$-FA-MeAra (3) or of FA-MeAra-(8-O-4)-FA (3'). The absence of the deprotonated FA ion in the $\mathrm{MS}^{2}$ spectra of the two other pairs argues for more resistant interunit bonds. From the $\mathrm{MS}^{2}$ spectra, peak pair $\mathbf{1}$ could be assigned to DFA conjugates bearing an 8-5 bond in a so-termed noncyclic structure and referred to as FA- $(8-5 n c)-F A-M e A r a ~(1)$ or as FA-MeAra$(8-5 n c)-F A\left(\mathbf{1}^{\prime}\right)$ (Figure $\left.1 \mathrm{E}\right)$. These spectra had ion fragments at $m / z 487,472,457$, and 341 resulting from decarboxylation, demethylation, and sugar loss, as well as a major and diagnostic ion at $m / z$ 323. This $m / z 323$ ion originates from the dehydration of the ion at $m / z 341$, a reaction that proceeds via the formation of a phenolic lactone and is characteristic of the $8-5 \mathrm{nc}$ bonding pattern. ${ }^{13}$ Each anomer associated with peak pair 2 displayed very little fragmentation of its $[\mathrm{M}-\mathrm{H}]^{-}$ion (Figure $1 \mathrm{~F}$ ). This stability supports the hypothesis that they are the $\beta$ - and $\alpha$-anomers of FA-(5-5)-FA-MeAra. Not unexpectedly when they are analyzed on a C18-HPLC column, the relative elution order of these DFA-MeAra conjugates is the same as that of their aglycones: i.e., $8-5 \mathrm{nc}<5-5<8-O-4 .^{13,17}$ Although the current identification of these three DFA isomers esterified with one methylarabinose relies only upon mass spectral data, it is conclusively supported by the analyses of the corresponding DFA aglycones obtained by subjecting the acidolysis mixture to alkaline hydrolysis, as explained in the following. What we are not able to unequivocally determine, however, is the regiochemistry of the MeAra substitution: i.e., which of the two FA moieties (in an unsymmetrical DFA) remains esterified. When only one of the two regioisomers is available, analysis of the MS fragmentation does not reliably reveal which FA moiety is esterified, as the same losses can be rationalized from both. In their original state in the plant, both ferulate moieties are esterified in all of the DFAs. We imagine that MeAra on a free phenolic unit might hydrolyze more readily, but in some of the DFAs, both units are free phenolic. At some point we hope to tackle this conundrum, perhaps by modeling but also by subjecting isolated or synthesized DFAdiMeAra compounds to this mild acidolysis followed by careful NMR analysis of the products. For now, delineating which of the mono-MeAra regioisomers is present appears to be indeterminate.

On the LC-MS trace reconstructed at $m / z 677$ (Figure 1D), isomers eluted as the peak cluster labeled 4 displayed the same $\mathrm{MS}^{2}$ spectra with almost no fragments, which suggests that they are a mixture of FA-MeAra-(5-5)-FA-MeAra anomers (Figure $1 \mathrm{H}$ ). For peak cluster $\mathbf{5}, \mathrm{MS}^{2}$ spectra harboring a small fragment at $m / z 531$ resulting from MeAra loss and a major FA-MeAra ion fragment at $\mathrm{m} / z 339$ (Figure 1I) were obtained. On this basis, the corresponding DFA isomers most likely comprise two FA-MeAra units interconnected by a labile (8$\mathrm{O}-4$ ) bond, referred to as FA-MeAra-(8-O-4)-FA-MeAra (Figure 1I). Both DFA diester types would occur as a mixture of four anomers. The 5-5-DFA compound 4, because of its center of symmetry, would have three peaks $(\beta \beta, \beta \alpha=\alpha \beta$, $\alpha \alpha)$; if these are in the $\sim 40: 60$ ratio of the anomers for compounds 1-3 (Figure 1C), the three peaks would be in a ratio of $\sim 16: 48: 36$, roughly as seen here for peaks 4 in Figure 1D. The 8-O-4-DFA compound 5 should have four physically different isomers, three of which are resolved. Upon examination of the third peak in the 4/5 cluster, it is clear that it contains signatures of both $\mathbf{4}$ and $\mathbf{5}$, indicating that all four isomers for $\mathbf{5}$ are resolved from each other but that the leftmost peak overlaps with the rightmost peak from 4 on the LC-MS trace. These peaks have been labeled with their likely anomeric assignments in Figure 1D. In contrast to DFA isomers acylating an arabinofuranose unit with a free $\mathrm{OH}$ group at $C-1$, the $\mathrm{MS}^{2}$ spectra of these DFA-MeAra conjugates do not display any fragment ion assignable to the cross-ring cleavage of the furanose ring.

The identification of these DFA units esterified with two MeAra units in the acidolysis products of extract-free maize bran not only is supported by mass spectral data but also is consistent with the isolation of their nonmethylated analogues: i.e., diarabinosyl- $(5-5)-\mathrm{DFA}^{18}$ and diarabinosyl- $(8-O-4)$ $\mathrm{DFA}^{19}$ from maize bran cell walls subjected to acidolysis without methanol. Modeling experiments have revealed that the 5-5-DFA, perhaps uniquely among the dimers, may be formed between two close FA esters from the same $\mathrm{AX}$ chain. $^{20}$ This intramolecular bonding possibility means that the identification of 5-5-DFA isomers esterified with two sugar units, e.g., 4 (Figure $1 \mathrm{H}$ ), cannot prove that this DFA mediates the cross-linking of two different AX chains. ${ }^{5}$ In contrast, both the previously identified diarabinosyl- $(8-O-4)-D_{F A}^{19}$ and the currently recovered FA-MeAra-(8-O-4)-FA-MeAra (5; 

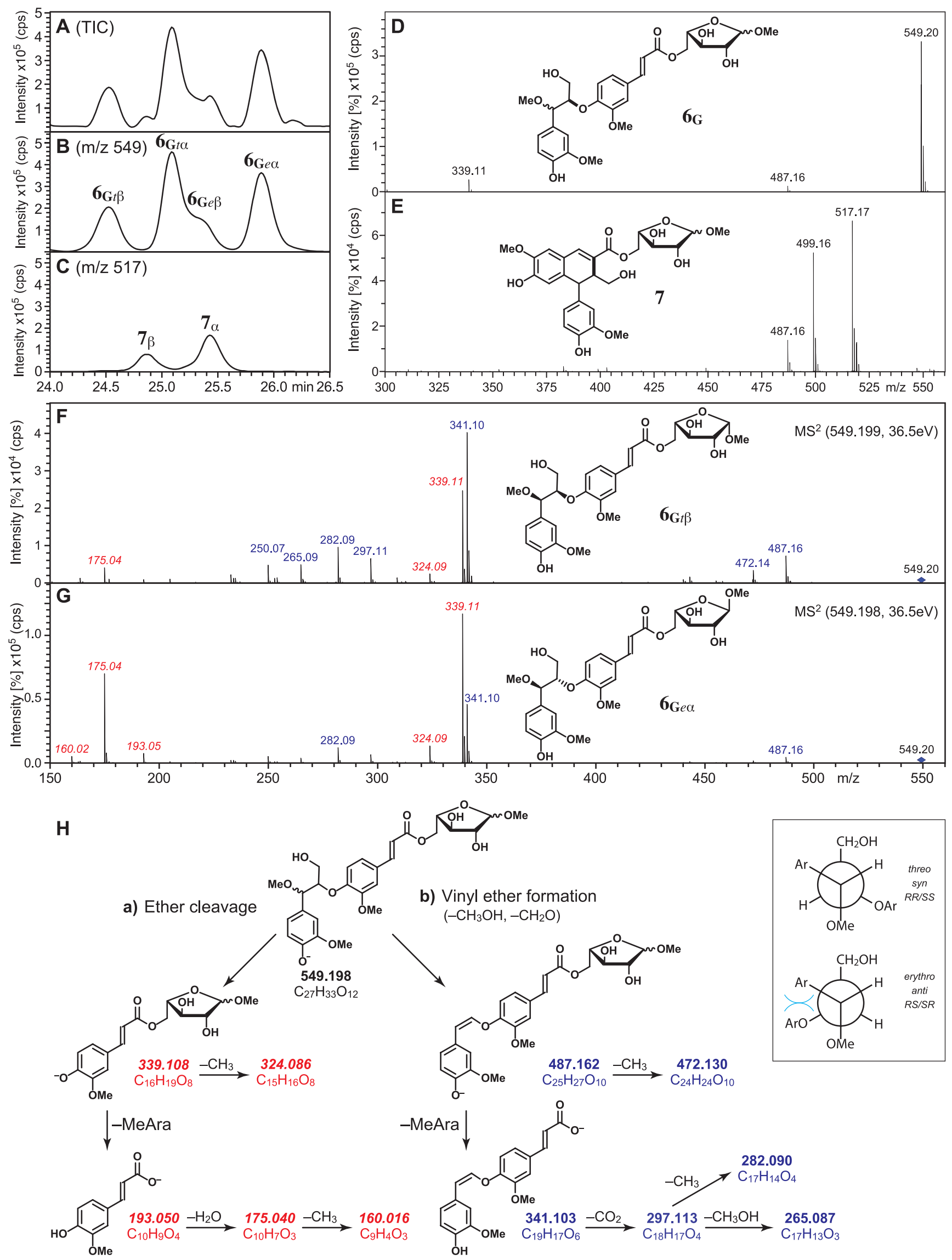

Figure 2. LC-MS analysis (ESI negative ion mode) of the late-eluting peak cluster observed from the acidolysis of lignified miscanthus internodes. The three partial chromatograms are shown with the same intensity scale and correspond to (A) a total ion chromatogram, (B) a chromatogram reconstructed at $m / z 549$ with four resolved isomeric components (peak pairs $\mathbf{6}_{\mathrm{G} t}$ and $\mathbf{6}_{\mathrm{G} e}$ ), and (C) a chromatogram reconstructed at $m / z 517$ 
Figure 2. continued

with two isomeric components (peak pair 7). The mass spectra of peaks $\mathbf{6}_{\mathrm{G} e}$ and 7 (first isomer) are shown in (D) and (E), respectively. The MS ${ }^{2}$ spectra of isomers corresponding to peak $\mathbf{6}_{\mathrm{G} t \beta}$ and to peak $\mathbf{6}_{\mathrm{G} e \alpha}$ are shown in (F) and (G), respectively (ion $m / z 549.198$ fragmented at CE 36.5 $\mathrm{eV})$. The corresponding fragmentation scheme is proposed in $(\mathrm{H})$ with the molecular formula obtained from accurate mass measurements; pathway a proceeds by an ether cleavage and pathway b by the formation of a vinyl ether ion; ions from pathway a are indicated in italics in ( $\mathrm{F})-$ $(\mathrm{H})$. Vertical axis scales are given in cps (counts per second).

(8-O-4)-DFA-diMeAra) are a definite indication that $(8-$ $O-4)$-DFA units cross-link two different AX chains in grass cell walls. The peaks of FA-(8-O-4)-FA-MeAra (3) (or its isomer $\left.3^{\prime}\right)$ and of FA-MeAra-(8-O-4)-FA-MeAra (5) were found to have similar areas, when they are measured on their specific extracted-ion chromatograms (Figures 1C,D, respectively). This result suggests that, during acidolysis, hydrolysis of ester bonds occurred, but to a limited extent. Even though this LC-MS investigation was focused on the main peaks assignable to DFA mono- and diesters and does not include minor peaks assignable to other DFA conjugates, this investigation emphasizes that the mild acidolysis procedure has the potential to provide a wealth of information about DFA units ester-linked to grass cell walls from a few milligrams of a sample.

Release by Mild Acidolysis of New Arabinose Conjugates Diagnostic of Ferulate-Monolignol CrossCoupling in Lignified Grass Samples. As shown on the expanded chromatograms of Figure $2 \mathrm{~A}-\mathrm{C}$, the peak cluster observed at the end of the LC-MS traces of lignified samples mainly comprised of compound $\mathbf{6}$ with four resolved isomers with $[\mathrm{M}-\mathrm{H}]^{-}$ions at $\mathrm{m} / z 549$ (accounting for about $80 \%$ of the cluster) together with a compound 7 with two more resolved minor isomers with $[\mathrm{M}-\mathrm{H}]^{-}$ions at $m / z 517$. Their UV spectra were ferulate-like, with a maximum close to 320 $\mathrm{nm}$ and a shoulder close to $280 \mathrm{~nm}$. The four isomers with $[\mathrm{M}-\mathrm{H}]^{-}$ions at $m / z 549.198 \quad\left(\mathrm{C}_{27} \mathrm{H}_{33} \mathrm{O}_{12}{ }^{-}\right.$elemental formula) displayed very similar ESI mass spectra with a small fragment ion at $m / z 339$, assignable to the FA-MeAra anion (Figure 2D). These spectral data suggest that these four isomers are made of FA-MeAra linked to another component. As these isomers were more specifically released from lignified samples (miscanthus or maize), they most likely include a lignin-derived unit. From the FA-MeAra ion at $\mathrm{m} / z$ 339, we made the reasonable hypothesis that this lignin-derived unit was linked to FA-MeAra via a bond that can be cleaved during ESI analysis and logically arrived at structure $\mathbf{6}_{\mathrm{G}}$ in Figure $2 \mathrm{D}$. This structure associates a guaiacyl $(\mathrm{G})$ unit methylated at its benzylic position (referred to as an MeG unit) to FA-MeAra and via a $\beta-O-4$ linkage; the compound therefore arises from the radical coupling of coniferyl alcohol with the ferulate ester. Methoxyl groups at the benzylic position of the $\mathrm{G}$ unit and at the arabinose $C-1$ are introduced during acidolysis performed in the presence of methanol. Such heterodimers, referred to as MeG- $(\beta-O-4)$-FA-MeAra $\left(6_{\mathrm{G}}\right)$, would occur as eight different isomers, i.e., the erythro (anti, $R S / S R$ ) or threo (syn, RR/ $S S$ ) diastereoisomer, ${ }^{21}$ each associated with the $\beta$ - or $\alpha$-MeAra anomer; as expected from chiral centers so well separated, the HPLC resolves four peaks, the $\alpha$ - and $\beta$-methylarabinosyl anomers of the threo- and erythro- $\beta$-ethers, as assigned in Figure 2B. The $\mathrm{MS}^{2}$ spectra of these four isomers were obtained in the negative ion mode (Figure $2 \mathrm{~F}, \mathrm{G}$ ). Isomers corresponding to peak pair $\mathbf{6}_{\mathrm{G} t}$ (i.e., $\mathbf{6}_{\mathrm{G} t \beta}$ and $\mathbf{6}_{\mathrm{G} t \alpha}$, Figure $2 \mathrm{~B}$ ) displayed very similar $\mathrm{MS}^{2}$ spectra (Figure $2 \mathrm{~F}$ ), as did the isomers corresponding to peak pairs $\mathbf{6}_{\mathrm{G} e}$ (i.e., $\mathbf{6}_{\mathrm{G} e \beta}$ and $\mathbf{6}_{\mathrm{G} e \alpha}$,
Figure 2B) in Figure 2G. As the anomeric configuration of MeAra is unlikely to substantially affect the $\mathrm{MS}^{2}$ spectra, each peak pair $\left(\mathbf{6}_{\mathrm{G} t}\right.$ or $\left.\mathbf{6}_{\mathrm{Ge}}\right)$ most likely corresponds to homologous $(\beta, \alpha)$ anomers in which the $\beta$-anomer is eluted first and the $\beta$ ether unit has the same stereochemistry, as labeled in Figure $2 \mathrm{~B}$. From these $\mathrm{MS}^{2}$ spectra, a mass fragmentation pattern could be drawn (Figure $2 \mathrm{H}$ ), with pathways proceeding either via the cleavage of the $\beta-O-4$-ether bond (pathway a) or via the formation of a vinyl ether ion (pathway $b$ ). The FA-MeAra $[\mathrm{M}-\mathrm{H}]^{-}$ion at $m / z 339$ or the vinyl ether ion at $m / z 487$ would be further fragmented through the loss of an MeAra unit. The relative intensities of ions associated with vinyl ether formation (at $m / z 487,472,341,297,282$, and 265) were more pronounced for anomers $\mathbf{6}_{\mathrm{G} t}$ than for anomers $\mathbf{6}_{\mathrm{G} e}$. Taken together, these results support the hypothesis that anomeric pairs, labeled $\mathbf{6}_{\mathrm{G} t}$ and $\mathbf{6}_{\mathrm{G} e}$, are most likely the threo and erythro forms of the $\beta$-ether unit, as indicated in Figure 2. The assignment of threo and erythro isomers is quite sound because it has been previously noted that threo- $\beta$-ether isomers generally elute more quickly and have more prominent fragment ions from vinyl ether degradation pathways, as the required anti elimination geometry is less sterically encumbered (see the stereodiagram rationale in Figure $2 \mathrm{H}$ ). ${ }^{22,23}$

Two other feruloylated isomers with an $[\mathrm{M}-\mathrm{H}]^{-}$ion at $\mathrm{m} / z$ 517 (peak pair 7 in Figure 2C) partially coeluted with the four MeG-( $\beta-O-4)$-FAMeAra isomers, but their relative areas were 4-5-fold lower, as evaluated from the areas of their specific peaks (measured on extracted-ion chromatograms). These components with similar ESI spectra were identified as the aryltetralin $\beta$ - and $\alpha$-anomers, arising from $\beta-8$ coupling of coniferyl alcohol to ferulate, referred to as $\mathrm{G}-(\beta-8 \mathrm{c})$-FAMeAra (7) isomers as shown in Figure 2E. In addition to the $[\mathrm{M}-\mathrm{H}]^{-}$ion at $m / z 517.172\left(\mathrm{C}_{26} \mathrm{H}_{29} \mathrm{O}_{11}{ }^{-}\right)$, their mass spectra displayed two ions at $m / z 499$ and 487 from $\mathrm{H}_{2} \mathrm{O}$ and $\mathrm{CH}_{2} \mathrm{O}$ loss, respectively. Their $\mathrm{MS}^{2}$ spectra displayed many fragment ions originating from $\mathrm{H}_{2} \mathrm{O}, \mathrm{CH}_{2} \mathrm{O}$, and $\mathrm{CH}_{3}$ losses as well as the $m / z 341$ ion generated from the $m / z 487$ ion fragment via MeAra loss.

Besides the MeG-( $\beta-O-4)$-FA-MeAra isomers $\mathbf{6}_{\mathrm{G}}$, their syringyl (S) analogues, referred to as $\mathrm{MeS}-(\beta-O-4)$-FA$\operatorname{MeAra}\left(6_{S}\right)$, were evidenced as minor components and in the LC-MS ion chromatograms reconstructed at $\mathrm{m} / z 579$ (not shown, but see the next section for proof of $S$ analogues). Their $[\mathrm{M}-\mathrm{H}]^{-}$ion was at $m / z 579.209\left(\mathrm{C}_{28} \mathrm{H}_{35} \mathrm{O}_{13}{ }^{-}\right.$ elemental formula). Similarly to their $\mathrm{G}$ analogues, their $\mathrm{MS}^{2}$ spectra displayed ions originating from $\beta$-ether cleavage (at $m / z 339,193$, and 175$)$ or from the formation of a vinyl ether ion (at $m / z 517,502$, and 371). From chromatograms reconstructed at $m / z 579$ and at $m / z 549$, the areas of the $\mathrm{SMe}$ conjugates released from miscanthus internodes or from maize stem was found to be about 10-fold lower than the areas of their $\mathrm{G}$ analogues. Taken together, the $\mathrm{MS}^{2}$ analyses of the isomers provided with $[\mathrm{M}-\mathrm{H}]^{-}$ions at $\mathrm{m} / z 549,517$, and 579 strongly supports their assignments as corresponding to MeG$(\beta-O-4)$-FA-MeAra $\left(6_{\mathrm{G}}\right), \mathrm{G}-(\beta-8 \mathrm{c})$-FA-MeAra $(7)$, and 


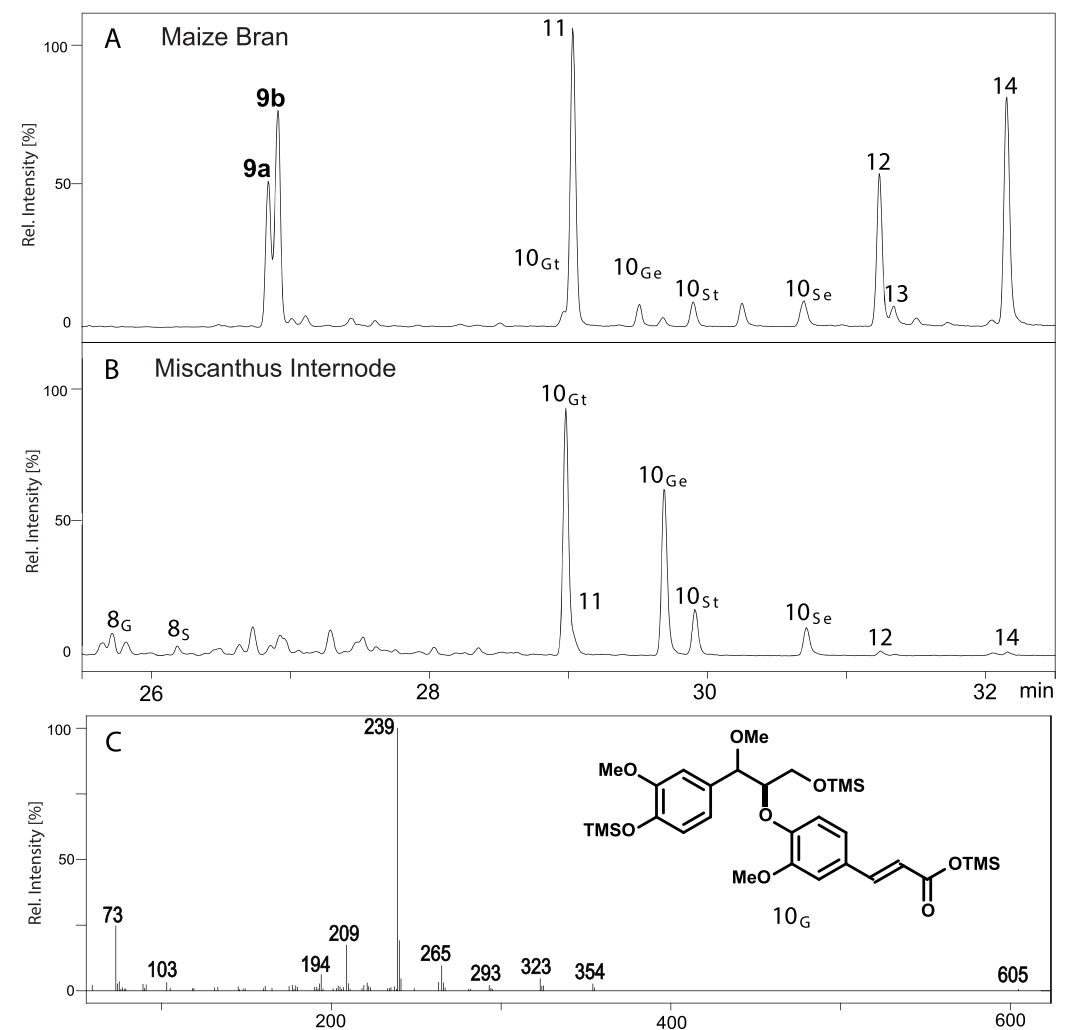

Figure 3. GC-MS analyses (total-ion chromatograms) of the phenolic dimers (analyzed as their TMS derivatives) recovered from extractive-free (A) maize bran and (B) miscanthus internodes successively subjected to acidolysis and alkaline hydrolysis. Numbers refer to mass spectral identifications from Table 1 . In (C), the mass spectrum of peak $\mathbf{1 0}_{G}$, the trimethylsilylated aglycone of $\mathbf{6}_{\mathbf{G}}$ (Figure 2 ), is shown together with the corresponding structure; the spectrum for each isomer (not shown) was similar.

Table 1. GC-MS Analysis (Electron Impact $70 \mathrm{eV}$ ) of the TMS Phenolic Dimers (Analyzed as Their TMS Derivatives) Recovered after Alkaline Hydrolysis of Acidolysis Samples ${ }^{a}$

\begin{tabular}{|c|c|c|c|c|}
\hline peak & assignment & $\mathrm{RT}(\min )$ & $\begin{array}{l}\mathrm{M}^{+}(m / z) \\
\text { (intens (\%)) }\end{array}$ & other ions $(m / z)($ rel intens $(\%))$ \\
\hline $8_{\mathrm{G}}$ & $\mathrm{G}-(\beta-8 \mathrm{c})-\mathrm{FA}^{b}$ & 25.72 & $660(\mathrm{ND})$ & $\begin{array}{l}645(12), 570(57), 541(13), 526(9), 480(9), 467(41), 453(12), 425(9), 410(27), \\
\quad 392(17), 380(13), 103(5), 73(100)\end{array}$ \\
\hline $8_{\mathrm{S}}$ & $\mathrm{S}-(\beta-8 \mathrm{c})-\mathrm{FA}^{b}$ & 26.49 & $690(\mathrm{ND})$ & $\begin{array}{l}675(12), 600(100), 587(28), 570(9), 556(12), 541(10), 497(42), 493(13), 467(5) \text {, } \\
\quad 455(8), 440(36), 410(20), 103(4), 73(95)\end{array}$ \\
\hline $9 \mathrm{a}, \mathrm{b}$ & $(8-8 \mathrm{c})-\mathrm{DFA}^{c}$ & $26.84 / 26.90$ & $674(\mathrm{ND})$ & $\begin{array}{l}659(19), 557(81), 556(98), 541(14), 526(9), 513(11), 467 \text { (75), } 425(8), 410(20) \\
\quad 380(10), 273(13), 147(8), 73(100)\end{array}$ \\
\hline $10_{\mathrm{G}}$ & $\begin{array}{l}\mathrm{GMe}-(\beta-O-4)-\mathrm{FA}^{b} \\
\text { threo/erythro }\end{array}$ & $28.97 / 29.69$ & $620(\mathrm{ND})$ & $\begin{array}{l}605(1), 354(4), 323(6), 293(2), 265(10), 239 \text { (100), } 209 \text { (17), } 194(6), 179 \text { (2), } 147 \text { (2), } \\
103(3), 73(24)\end{array}$ \\
\hline 11 & $(8-5 n c)-D_{F A}^{c}$ & 29.03 & $674(95)$ & 659 (95), 569 (4), 465 (9), $423(10), 407$ (10), 395 (10), 367 (10), 147 (34), 73 (100) \\
\hline $10_{\mathrm{s}}$ & $\begin{array}{l}\text { SMe- }(\beta-O-4)-\mathrm{FA}^{b} \\
\text { threo/erythro }\end{array}$ & $29.91 / 30.70$ & $650(1)$ & $\begin{array}{l}635(1), 384(3), 353(5), 325(3), 295(4), 269 \text { (100), } 239 \text { (18), } 252(4), 224 \text { (9), } 209 \text { (4), } \\
\quad 147(4), 103(3), 73(15)\end{array}$ \\
\hline 12 & $(8-O-4)-\mathrm{DFA}^{c}$ & 31.23 & $602(68)$ & $\begin{array}{l}587(15), 484(100), 457(19), 394(41), 364 \text { (19), } 353 \text { (7), } 337 \text { (12), } 281 \text { (18), } 251 \text { (7), } \\
\quad 147(5), 73(75)\end{array}$ \\
\hline 13 & $(8-5 c)-D_{F A}{ }^{c}$ & 31.33 & $602(30)$ & 587 (13), 543 (2), 512 (100), 497 (9), 484 (19), 482 (15), 393 (17), 73 (100) \\
\hline 14 & $(5-5)-\mathrm{DFA}^{c}$ & 32.16 & $674(100)$ & 659 (20), 569 (8), 497 (34), 495 (10), 479 (9), 407 (65), 379 (30), 364 (5), 73 (70) \\
\hline
\end{tabular}

${ }^{a}$ Peak numbers refer to peak notations in Figure 3. ND: not detected. ${ }^{b}$ Hypothetical assignment from mass fragmentation pattern. ${ }^{c}$ Assignment by comparison to published data. ${ }^{24,33}$

MeS- $(\beta-O-4)-F A-M e A r a\left(6_{S}\right)$ conjugates, respectively. These structural assignments were confirmed by GC-MS analyses of the corresponding aglycone forms, as explained in the following section relating to Figure 3.

GC-MS and LC-MS Analyses of the Dimeric Phenolics Recovered after Alkaline Hydrolysis of Acidolysis Samples. For further confirmation of the identifications made by LC-MS analyses, we subjected acidolysis mixtures to a mild alkaline hydrolysis in order to eliminate the MeAra moiety and examined the recovered phenolic aglycones. By removing the sugar residue, we intended to reduce the number of isomeric forms and to analyze the recovered low-molecularweight phenolics by GC-MS.

The GC-MS chromatograms of the phenolic dimers (analyzed as their TMS derivatives) released by alkaline hydrolysis of acidolysis samples are outlined in Figure 3. It is noteworthy that compounds assignable to peaks 8-14 in Figure 3 were not observed when the initial acidolysates were subjected to the same GC-MS analysis. This means that these compounds do not occur as free acids in the initial acidolysis 


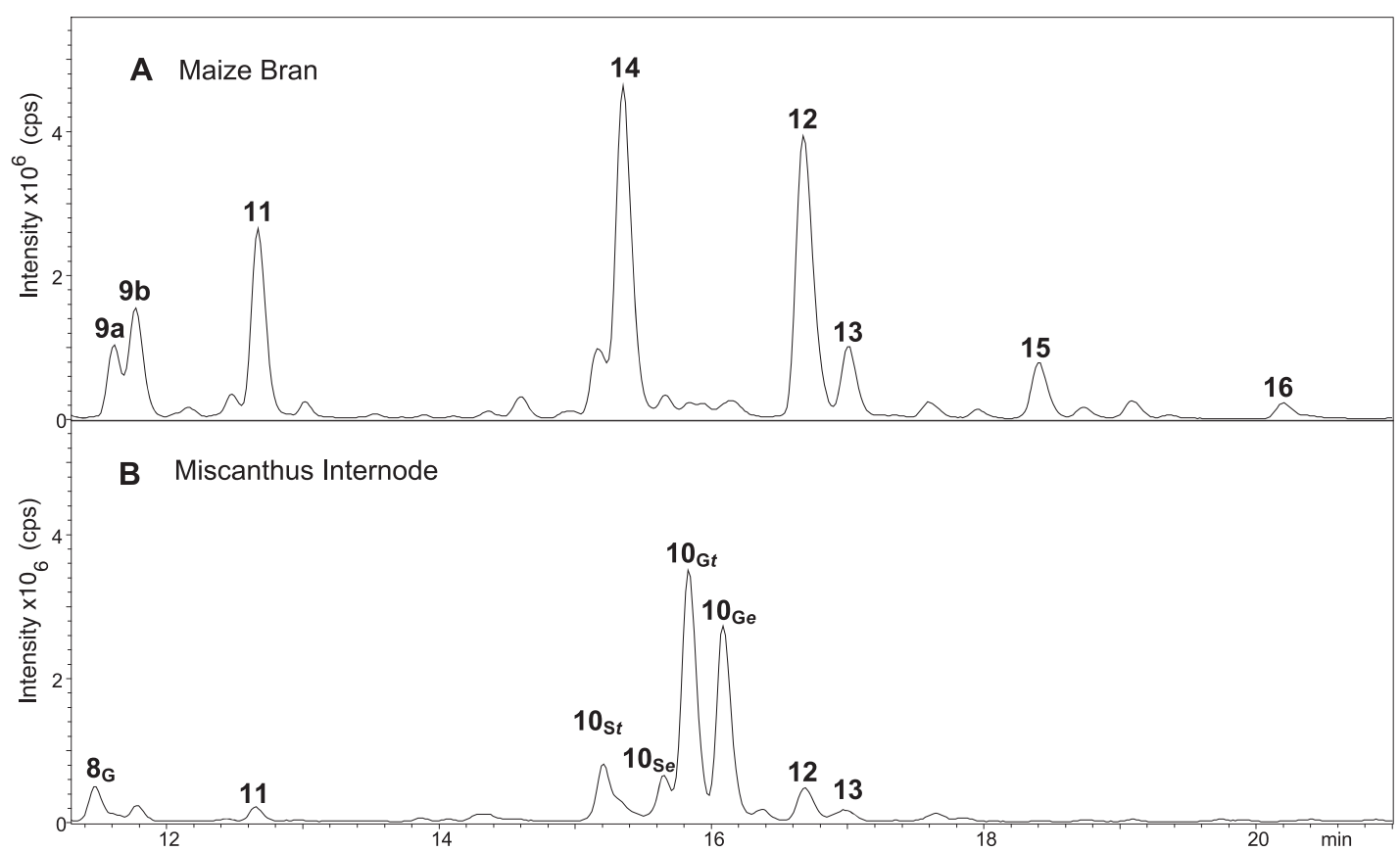

Figure 4. Partial LC-MS total ion chromatograms (negative ion mode) showing the separation of the main low-molecular-weight dimeric and trimeric phenolics recovered after alkaline hydrolysis of the acidolysis products from extract-free (A) maize bran sample and (B) miscanthus lignified internodes. The peak numbers refer to Table 2. Vertical axis scales are given in cps (counts per second).

Table 2. HPLC-MS Analysis (Electrospray Ionization, Negative Ion Mode) of the Low-Molecular-Weight Dimeric and Trimeric Compounds Recovered after Acidolysis Followed by Mild Alkaline Hydrolysis of Extract-Free Grass Cell Walls ${ }^{a}$

\begin{tabular}{|c|c|c|c|c|c|c|c|c|}
\hline peak & assignment & $\mathrm{RT}(\mathrm{min})$ & MW & $\begin{array}{l}{[\mathrm{M}-\mathrm{H}]^{-} \text {elemental }} \\
\quad \text { formula }\end{array}$ & $\begin{array}{c}{[\mathrm{M}-\mathrm{H}]^{-} \text {obsd }} \\
\quad(\mathrm{m} / z)\end{array}$ & $\begin{array}{c}{[\mathrm{M}-\mathrm{H}]^{-}} \\
\text {calcd }(m / z)\end{array}$ & $\begin{array}{l}\text { error } \\
(\mathrm{ppm})\end{array}$ & $\begin{array}{l}\text { main ions in ESI mass spectrum } \\
(m / z)(\text { rel intens }(\%))\end{array}$ \\
\hline $8_{\mathrm{G}}$ & $\mathrm{G}-(\beta-8 \mathrm{c})-\mathrm{FA}^{b}$ & 11.5 & 372 & $\mathrm{C}_{20} \mathrm{H}_{19} \mathrm{O}_{7}$ & 371.1136 & 371.1135 & 0.2 & $371(100) ; 353(8) ; 341(15)$ \\
\hline $9 a / 9 b$ & $(8-8 \mathrm{c})-\mathrm{DFA}^{c}$ & $11.6 / 11.8$ & 386 & $\mathrm{C}_{20} \mathrm{H}_{17} \mathrm{O}_{8}$ & 385.0924 & 385.0929 & 1.4 & $385(20) ; 341(100)$ \\
\hline 11 & $(8-5 n c)-D F A^{c}$ & 12.7 & 386 & $\mathrm{C}_{20} \mathrm{H}_{17} \mathrm{O}_{8}$ & 385.092 & 285.0929 & 2.3 & $385(100) ; 341(15) ; 297(2)$ \\
\hline $10_{S t}$ & $\mathrm{SMe}-(\beta-O-4)-\mathrm{FA}^{b}$ & 15.2 & 434 & $\mathrm{C}_{22} \mathrm{H}_{25} \mathrm{O}_{9}$ & 433.1505 & 433.1504 & 0.3 & $433(100) ; 371(96) ; 193(15.1)$ \\
\hline 14 & $(5-5)-\mathrm{DFA}^{c}$ & 15.4 & 386 & $\mathrm{C}_{20} \mathrm{H}_{17} \mathrm{O}_{8}$ & 385.0923 & 385.0929 & 1.3 & $385(100)$ \\
\hline $10_{S e}$ & $\mathrm{SMe}-(\beta-O-4)-\mathrm{FA}^{b}$ & 15.6 & 434 & $\mathrm{C}_{22} \mathrm{H}_{25} \mathrm{O}_{9}$ & 433.1502 & 433.1504 & 0.5 & $433(100) ; 371(45) ; 193(57)$ \\
\hline $10_{\mathrm{G} t}$ & GMe- $(\beta-O-4)-\mathrm{FA}^{b}$ & 15.8 & 404 & $\mathrm{C}_{21} \mathrm{H}_{23} \mathrm{O}_{8}$ & 403.1396 & 403.1398 & 0.5 & $403(100) ; 341(72) ; 193(11)$ \\
\hline $10_{\mathrm{Ge}}$ & $\mathrm{GMe}-(\beta-O-4)-\mathrm{FA}^{b}$ & 16.1 & 404 & $\mathrm{C}_{21} \mathrm{H}_{23} \mathrm{O}_{8}$ & 403.1401 & 403.1398 & 3.0 & 403 (100); $341(40) ; 193(48)$ \\
\hline 12 & $(8-O-4)-\mathrm{DFA}^{c}$ & 16.7 & 386 & $\mathrm{C}_{20} \mathrm{H}_{17} \mathrm{O}_{8}$ & 385.0921 & 385.0928 & 2.2 & $\begin{array}{l}385(43) ; 341(4) ; 313(12) ; 193 \\
\quad(100)\end{array}$ \\
\hline 13 & $(8-5 c)-D_{F A}^{c}$ & 17 & 386 & $\mathrm{C}_{20} \mathrm{H}_{17} \mathrm{O}_{8}$ & 385.0927 & 385.0929 & 0.4 & $385(45) ; 341(100) ; 297(3)$ \\
\hline 15 & TFA $^{c}$ & 18.4 & 578 & $\mathrm{C}_{30} \mathrm{H}_{25} \mathrm{O}_{12}$ & 577.1344 & 577.1351 & 1.4 & $577(100) ; 533(4)$ \\
\hline 16 & $\mathrm{TFA}^{c}$ & 20.2 & 578 & $\mathrm{C}_{30} \mathrm{H}_{25} \mathrm{O}_{12}$ & 577.134 & 577.1351 & 2 & $577(100) ; 383(4) ; 193(20)$ \\
\hline
\end{tabular}

${ }^{a}$ Peak numbers refer to peak notations from Figure 4 and Table 1 . Note: Peaks are given in the table in their elution order, which is different from those of their TMS derivatives in Table 1 and Figure $3 .{ }^{b}$ Assignment from mass fragmentation pattern. ${ }^{c}$ Assignment by comparison to published elution order ${ }^{17}$ and mass spectral data. ${ }^{34}$

sample but are in their esterified forms (with a sugar unit) that makes their direct GC analysis impossible. The two chromatographic traces obtained from the maize bran sample (Figure $3 \mathrm{~A}$ ) and the lignified miscanthus sample (Figure 3B) were quite different. Consistently with the LC-MS profile, the main phenolic dimers from maize bran were DFA isomers unambiguously identified from the mass spectra of their TMS derivatives (Figure $3 \mathrm{~A}$ and Table 1), in comparison to published spectra. ${ }^{24}$ These DFA dimers were the $(8-8 \mathrm{c})$-DFA (9a,b; cis and trans isomers), (8-5nc)-DFA (11), (8-O-4)DFA (12), (8-5c)-DFA (13), and (5-5)-DFA (14). The authentication of these DFA isomers as the main diferulates (Figure 3A) of the maize bran trace conclusively supports the identification of the corresponding DFA structures acylating one or two MeAra groups in the acidolysis products from maize bran in Figure 1A.

In the case of lignified grass samples, the main diphenolic compounds were associated with two peaks $1 \mathbf{1 0}_{\mathrm{G}}$ that displayed essentially identical mass spectra (Figure 3C). From their mass spectra, these isomers could easily be identified as the threo and erythro diastereoisomers involving a guaiacyl unit in which the benzylic $-\mathrm{OH}$ appears methylated (although the unit actually derives from methoxylation at the benzylic carbon) and is linked to an FA unit in a $\beta$-ether structure, referred to as GMe- $(\beta-O-4)-\mathrm{FA}\left(\mathbf{1 0}_{\mathrm{G}}\right)$. This identification was based on comparison with published mass spectra of heterodimers involving a guaiacyl unit ether-linked to a ferulate. ${ }^{1}$ The spectra of GMe- $(\beta-O-4)-\mathrm{FA}\left(\mathbf{1 0}_{\mathrm{G}}\right)$ and of $\mathrm{G}-(\beta-O-4)$-FA heterodimers (not shown), analyzed as TMS derivatives, displayed 
benzylic ions as base peaks, at $m / z 239$ and 297, respectively. Common ions for these heterodimers were at $\mathrm{m} / z \quad 103$ $\left(\mathrm{CH}_{2} \mathrm{OTMS}^{+}\right.$) and 323 (from the TMS-FA moiety). From the LC-MS observation (Figure 2B) that the threo isomers eluted first and were more abundant than their erythro analogues, we assume that the first prominent peak $\mathbf{1 0}_{\mathrm{G}}$ also corresponds to the threo isomer: i.e., it corresponds to $\mathbf{1 0}_{\mathrm{G} t}$. In addition to these $\mathrm{GMe}-(\beta-O-4)-\mathrm{FA} \mathbf{1 0}_{\mathrm{G}}$ isomers, the aryltetralin $\mathrm{G}$ and $\mathrm{S}$ isomers, $\mathrm{G}-(\beta-8 \mathrm{c})-\mathrm{FA}\left(\mathbf{8}_{\mathrm{G}}\right)$ and $\mathrm{S}-(\beta-8 \mathrm{c})-\mathrm{FA}\left(\mathbf{8}_{\mathrm{S}}\right)$ (Figure $3 \mathrm{~B})$, could be detected, as confirmed from their diagnostic mass spectra. Finally, the syringyl analogues of GMe- $(\beta-O-$ 4)-FA $\left(10_{\mathrm{G}}\right)$, referred to as SMe- $(\beta-O-4)$-FA $\left(10_{\mathrm{S}}\right)$, were assigned as labeled (Figure 3$)$. In agreement with LC-MS data, the areas of these SMe- $(\beta-O-4)$-FA $\left(\mathbf{1 0}_{\mathrm{S}}\right)$ diastereoisomers observed on the GC-MS miscanthus trace were found to be much lower than those of their $G$ analogues $\mathbf{1 0}_{\mathrm{G}}$. Not unexpectedly, the $10_{\mathrm{G}}$ and the $1 \mathbf{1 0}_{\mathrm{S}}$ isomers were both observed as minor peaks in the maize bran trace (Figure $3 \mathrm{~A}$ ), but strikingly enough and from their peak areas, $10_{S}$ isomers were found to dominate over their $\mathrm{G}$ analogues $\mathbf{1 0}_{\mathrm{G}}$ (Figure 3B). This intriguing result means that coniferyl alcohol is not always the main monolignol to cross-couple with FA esters in grass cell walls, with the distribution being tissue- and, presumably, maturity-dependent; although such cross-coupling is expected, the monolignol-ferulate cross-coupled dimers previously identified were mainly $\mathrm{G},{ }^{1,25,26}$ as reviewed. ${ }^{4}$

As a final control, the reaction mixture recovered after alkaline hydrolysis of acidolysates was subjected to LC-MS analyses. By so doing, we obtained results entirely consistent with those from GC-MS analyses. The main phenolic dimers identified by GC-MS of their TMS derivatives were easily recognized by LC-MS (Figure 4 and Table 2). The main dimers of the maize bran LC chromatogram (Figure 4A) were $(8-8 \mathrm{c})$-DFA (two isomers 9a,b), (8-5nc)-DFA (11), (5-5)DFA (14), (8-O-4)-DFA (12), and (8-5c)-DFA (13), in complete agreement with GC-MS analysis. In addition, two minor peaks (peaks 15 and 16) could be assigned to compounds that cannot be observed by GC-MS, namely triferulates (TFA). ${ }^{27}$ These TFA isomers were recognized from their $[\mathrm{M}-\mathrm{H}]^{-}$ion at $m / z 577$ (Table 2). The main dimers of the miscanthus LC trace were assignable to the threo/erythro isomers of $\mathrm{GMe}-(\beta-O-4)-\mathrm{FA}\left(\mathbf{1 0}_{\mathrm{G}}\right.$; two peaks, threo $\left(\mathbf{1 0}_{\mathrm{G} t}\right)$ and erythro $\left(\mathbf{1 0}_{\mathrm{Ge}}\right)$, Figure $\left.4 \mathrm{~B}\right)$. Their ESI mass spectra (Table 2) displayed an $[\mathrm{M}-\mathrm{H}]^{-}$ion at $\mathrm{m} / z 403$ together with a diagnostic FA ion at $\mathrm{m} / z 193$ resulting from $\beta$-ether cleavage. Their $\mathrm{MS}^{2}$ spectra displayed the same fragment ions, but with different relative intensities, and these ions originated either from $\beta$-ether cleavage or from the formation of a vinyl ether ion. Their syringyl analogues SMe- $(\beta-O-4)$-FA $\left(\mathbf{1 0}_{\mathrm{S}}\right)$ (Figure 4B) were associated with $[\mathrm{M}-\mathrm{H}]^{-}$ions at $\mathrm{m} / z 433$ and fragment ions at $m / z 471$ (from decarboxylation) and 193 (FA ion).

LC-UV Evaluation of the Main Phenolic Heterodimers Released by Acidolysis of Lignified Grass Samples. The combined LC-MS and GC-MS analyses provided conclusive evidence that the main methylarabinosylated dimers released by acidolysis of lignified grass cell walls are the isomers GMe$(\beta-O-4)$-FA-MeAra $\left(6_{\mathrm{G}}\right)$ diagnostic of the $\beta-\mathrm{O}-4$ crosscoupling of coniferyl alcohol to arabinoxylan-linked ferulate esters. The next step was to attempt their quantitative evaluation. As these exact authentic compounds are not available, we preferred to perform this evaluation by LC-UV rather than by LC-MS, recognizing that their amounts may be reasonably approximated from HPLC-UV traces and using the FA response factor, as previously demonstrated for the FAMeAra conjugates. ${ }^{6}$ In contrast, the ESI ionization efficiency may substantially vary with the structure of the phenolic compounds, which makes crucial the availability of authentic standard compounds or, ideally, multi-isotope-labeled analogues, ${ }^{28,29}$ for such MS-based quantification. The evaluation of the GMe- $(\beta-O-4)$-FA-MeAra $\left(6_{G}\right)$ isomers was not directly performed on their peak clusters but on the peak pair from their aglycones GMe- $(\beta-O-4)-F A\left(\mathbf{1 0}_{\mathrm{G}}\right)$. Reducing the isomer number to 2 improved both the HPLC separation and the signal to noise ratio of the peaks to be integrated. This evaluation revealed that the dimers diagnostic of the $\beta-O-4$ coupling of coniferyl alcohol to ferulate esters were obtained in substantial amounts from lignified extract-free miscanthus or maize samples, with values ranging between 0.5 and $1 \mathrm{mg} / \mathrm{g}$ when they are expressed on an FA-equivalent basis (Table 3).

Table 3. Amount of GMe-( $\beta-O-4)$-FA $10_{\mathrm{G}}$ Released by Successively Subjecting Extract-Free Lignified Grass Samples to Mild Acidolysis and Then Alkaline Hydrolysis, in Comparison to the Amount of FA Units Involved Only in Ester Bonds (FA-Ester Only) or Those Also Involved in Ether Bonds (FA-Ethers) ${ }^{a}$

\begin{tabular}{|c|c|c|c|}
\hline \multirow[b]{2}{*}{ extract-free sample } & \multicolumn{3}{|c|}{ FA equivalent $(\mathrm{mg} / \mathrm{g})$} \\
\hline & GMe- $(\beta-O-4)-\mathrm{FA}^{b}$ & FA-ester-only $^{c}$ & FA-ethers ${ }^{d}$ \\
\hline \multicolumn{4}{|c|}{ Miscanthus sinensis } \\
\hline lower internode & $1.06(0.02)$ & $3.43(0.14)$ & $6.09(0.63)$ \\
\hline whole stem & $0.78(0.04)$ & $3.84(0.12)$ & $6.25(0.22)$ \\
\hline leaves & $0.72(0.02)$ & $3.72(0.14)$ & $5.05(0.28)$ \\
\hline \multicolumn{4}{|c|}{ Miscanthus $x$ giganteus } \\
\hline whole stem & $0.80(0.03)$ & $3.56(0.26)$ & $5.74(0.50)$ \\
\hline leaves & $0.78(0.04)$ & $3.71(0.05)$ & $4.74(0.13)$ \\
\hline \multicolumn{4}{|c|}{ Maize Stem (Silage Stage) } \\
\hline F2 INRA line & $0.54(0.02)$ & $5.53(0.20)$ & $3.14(0.21)$ \\
\hline
\end{tabular}

${ }^{a}$ Data are mean values (SD) from at least three different analytical replicates. ${ }^{b}$ Released by mild acidolysis followed by mild alkaline hydrolysis. ${ }^{c}$ Evaluated by mild alkaline hydrolysis. ${ }^{d}$ Estimated from the difference between FA amounts released by severe and mild alkaline hydrolyses.

These cross-coupling products were recovered in similar amounts from stems and leaves of miscanthus harvested in February (Table 3), whereas they could not be quantified from the poorly lignified maize bran sample. That miscanthus leaves release substantial amounts of these cross-coupling products is a consequence of their fairly high lignin level ( $\sim 18 \%$ Klason lignin in extract-free samples).

For comparative purposes, Table 3 also provides the evaluations of FA units involved only in ester bonds and of FA units involved also in ether linkages with lignin units, according to a commonly used strategy. ${ }^{30,31}$ Whatever the sample, the amount of FA units incorporated into the acidolysis-derived GMe- $(\beta-O-4)$-FA dimer $\left(\mathbf{1 0}_{\mathrm{G}}\right)$ accounted for about $15 \%$ of the total amount of FA ethers. It is noteworthy that acidolysis ketones, which are the signatures of $\beta$-ether cleavage reactions in lignins, ${ }^{32}$ were detected in low amounts by GC-MS analysis (as their TMS derivatives) of the acidolysis mixture. This result indicates that $\beta$-ether cleavage occurred to a low extent during mild acidolysis and further supports the structures outlined in Figure 5 as the predominant precursors of the acidolysis GMe- $(\beta-O-4)-\mathrm{FA}-\mathrm{MeAra} \mathbf{6}_{\mathrm{G}}$ 


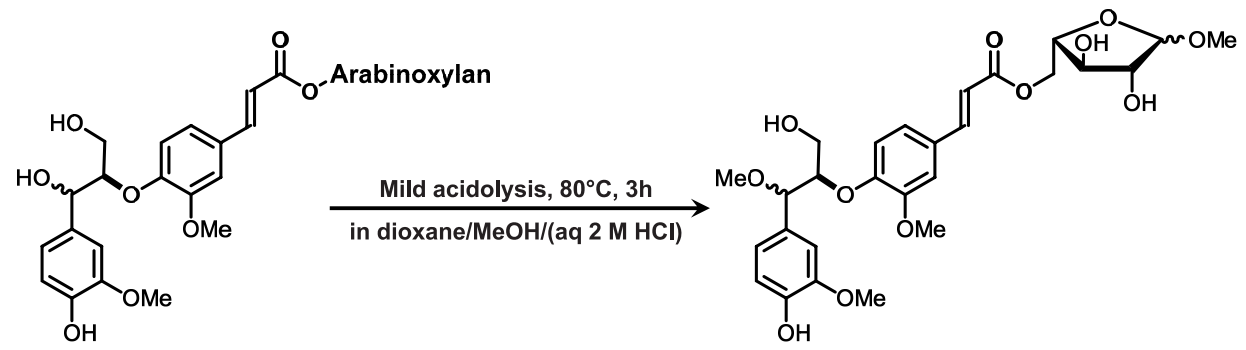

Figure 5. Most probable parent structures occurring in grass cell walls and giving rise to the MeG-(8-O-4)-FA-MeAra $\left(6_{\mathrm{G}}\right)$ isomers upon mild acidolysis.

isomers. These parent structures would comprise a ferulate unit esterified to arabinoxylans and etherified to a single $G$ unit.

To conclude, and in agreement with literature data, ${ }^{24}$ mild acidolysis from a poorly lignified grass sample allowed us to identify DFA homodimers esterified to one or two arabinose units, representing the $8-5,8-O-4$, and $5-5$ interunit bonding patterns. When mild acidolysis was performed on lignified grass cell walls, the main diphenolic conjugates were methylarabinosylated heterodimers originating from the oxidative cross-coupling of coniferyl alcohol and arabinoxylan-linked ferulate esters. Taken together, these results highlight the potential of mild acidolysis combined with LCMS and LC-UV analyses as a viable strategy to obtain valuable information regarding the FA-mediated cross-links established between the polymers of grass cell walls that crucially affect their biological properties and uses.

\section{ASSOCIATED CONTENT}

\section{S Supporting Information}

The Supporting Information is available free of charge on the ACS Publications website at DOI: 10.1021/acs.jafc.9b05840.

Main arabinose diphenolic conjugates obtained by mild acidolysis of grass samples and their aglycones, UV spectra of GMe- $(\beta-O-4)$-FA-MeAra $\left(6_{\mathrm{G}}\right)$ and GMe$(\beta-O-4)-\mathrm{FA}\left(\mathbf{1 0}_{\mathrm{G}}\right)$ isomers, $\mathrm{MS}^{2}$ spectra (negative ion mode) of G-( $\beta-8 \mathrm{c})$-FA-MeAra $(7)$ isomers, $\mathrm{MS}^{2}$ spectra (negative-ion mode) of GMe- $(\beta-O-4)-F A-$ $\operatorname{MeAra}\left(6_{\mathrm{G}}\right)$ and SMe- $(\beta-O-4)-\mathrm{FA}-\mathrm{MeAra}\left(6_{\mathrm{s}}\right)$ isomers, mass spectra (electron impact, $70 \mathrm{eV})$ of $\mathrm{G}-(\beta-$ $8 \mathrm{c})$-FA $\left(\mathbf{8}_{\mathrm{G}}\right)$ and $\mathrm{S}-(\beta-8 \mathrm{c})$-FA $\left(\mathbf{8}_{\mathrm{S}}\right)$ dimers (analyzed as their TMS derivatives), $\mathrm{MS}^{2}$ spectra (negative ion mode) of the GMe- $(\beta-O-4)-\mathrm{FA}\left(\mathbf{1 0}_{\mathrm{G}}\right)$ and SMe- $(\beta-$ $O-4)$-FA $\left(10_{S}\right)$ threo and erythro isomers, comparative $\mathrm{MS}^{2}$ spectra (negative- ion mode) of FA-(5-5)-FAMeAra, FA-(5-5)-FA-Ara, FA-MeAra-(5-5)-FAMeAr,a and FA-MeAra-(5-5)-FA-Ara, and relative area ratio of SMe- $(\beta-O-4)-\mathrm{FA}-\mathrm{MeAra}\left(6_{\mathrm{S}}\right)$ anomers to $\mathrm{GMe}-(\beta-O-4)$-FA-MeAra $\left(\mathbf{6}_{\mathrm{G}}\right)$ anomers released by acidolysis of lignified grass samples (PDF)

\section{AUTHOR INFORMATION}

\section{Corresponding Author}

*E-mail for C.L.: catherine.lapierre@agroparistech.fr.

ORCID $\odot$

Catherine Lapierre: 0000-0002-6757-1524

John Ralph: 0000-0002-6093-4521

Notes

The authors declare no competing financial interest.

\section{ACKNOWLEDGMENTS}

The IJPB benefits from the support of the LabEx Saclay Plant Sciences-SPS (ANR-10-LABX-0040-SPS). J.R. was funded by the DOE Great Lakes Bioenergy Research Center (DOE BER Office of Science DE-SC0018409). We sincerely thank Dr. Luc Saulnier (INRA Nantes) for providing the maize bran sample.

\section{ABBREVIATIONS}

AX, arabinoxylan; DFA, (dehydro)diferulate or (dehydro)diferulic acid; ESI, electrospray ionization; FA, ferulic acid or ferulate; FA-MeAra, methyl 5-O-feruloyl-L-arabinofuranoside; GC, gas chromatography; HPLC, high-performance liquid chromatography; Me-FA, methyl ferulate; Me- $p \mathrm{CA}$, methyl $p$ coumarate; MS, mass spectrometry; $p \mathrm{CA}, p$-coumaric acid or $p$-coumarate; $p$ CA-MeAra, methyl 5-O-p-coumaroyl-L-arabinofuranoside; TMS, trimethylsilyl

\section{REFERENCES}

(1) Jacquet, G.; Pollet, B.; Lapierre, C.; Mhamdi, F.; Rolando, C. New ether-linked ferulic acid-coniferyl alcohol dimers identified in grass straws. J. Agric. Food Chem. 1995, 43, 2746-2751.

(2) Ralph, J.; Grabber, J. H.; Hatfield, R. D. Lignin-ferulate crosslinks in grasses: active incorporation of ferulate polysaccharide esters into ryegrass lignins. Carbohydr. Res. 1995, 275, 167-178.

(3) de O. Buanafina, M. M. Feruloylation in grasses: Current and future perspectives. Mol. Plant 2009, 2, 861-872.

(4) Ralph, J. Hydroxycinnamates in lignification. Phytochem. Rev. 2010, 9, 65-83.

(5) Bento-Silva, A.; Patto, M. C. V.; Bronze, M. D. Relevance, structure and analysis of ferulic acid in maize cell walls. Food Chem. 2018, 246, 360-378.

(6) Lapierre, C.; Voxeur, A.; Karlen, S. D.; Helm, R. F.; Ralph, J. Evaluation of feruloylated and $p$-coumaroylated arabinosyl units in grass arabinoxylans by acidolysis in dioxane/methanol. J. Agric. Food Chem. 2018, 66, 5418-5424.

(7) Chateigner-Boutin, A. L.; Ordaz-Ortiz, J. J.; Alvarado, C.; Bouchet, B.; Durand, S.; Verhertbruggen, Y.; Barriere, Y.; Saulnier, L. Developing pericarp of maize: A model to study arabinoxylan synthesis and feruloylation. Front. Plant Sci. 2016, 7 (1476), 1-20.

(8) Sibout, R.; Le Bris, P.; Legee, F.; Cezard, L.; Renault, H.; Lapierre, C. Structural redesigning Arabidopsis lignins into alkalisoluble lignins through the expression of $p$-coumaroyl-CoA:monolignol transferase PMT. Plant Physiol. 2016, 170, 1358-1366.

(9) Lapierre, C.; Pollet, B.; Ralet, M. C.; Saulnier, L. The phenolic fraction of maize bran: evidence for lignin-heteroxylan association. Phytochemistry 2001, 57, 765-772.

(10) Smith, M. M.; Hartley, R. D. Occurrence and nature of ferulic acid substitution of cell-wall polysaccharides in graminaceous plants. Carbohydr. Res. 1983, 118, 65-80.

(11) Ishii, T. Isolation and characterization of a diferuloyl arabinoxylan hexasaccharide from bamboo shoot cell-walls. Carbohydr. Res. 1991, 219, 15-22. 
(12) Fry, S. C. Phenolic components of the primary cell wall: feruloylated disaccharides of $\mathrm{D}$-galactose and L-arabinose from spinach polysaccharide. Biochem. J. 1982, 203, 493-504.

(13) Callipo, L.; Cavaliere, C.; Fuscoletti, V.; Gubbiotti, R.; Samperi, R.; Lagana, A. Phenilpropanoate identification in young wheat plants by liquid chromatography/tandem mass spectrometry: Monomeric and dimeric compounds. J. Mass Spectrom. 2010, 45, 1026-1040.

(14) Chiremba, C.; Rooney, L. W.; Beta, T. Microwave-assisted extraction of bound phenolic acids in bran and flour fractions from sorghum and maize cultivars varying in hardness. J. Agric. Food Chem. 2012, 60, 4735-4742.

(15) Vismeh, R.; Lu, F.; Chundawat, S.; Humpula, J. F.; Azarpira, A.; Ralph, J.; Balan, V.; Dale, B. E.; Jones, A. D. Profiling of diferulates (plant cell wall cross-linkers) using ultrahigh-performance liquid chromatography-tandem mass spectrometry. Analyst 2013, 138, 6683-6692.

(16) Ostrowski, W.; Swarcewicz, B.; Nolka, M.; Stobiecki, M. Differentiation of phenylpropanoid acids cyclobutane- and dehydrodimers isomers in barley leaf cell walls with LC/MS/MS system. Int. J. Mass Spectrom. 2016, 407, 77-85.

(17) Waldron, K. W.; Parr, A. J.; Ng, A.; Ralph, J. Cell-wall-esterified phenolic dimers: Identification and quantification by reverse phase high performance liquid chromatography and diode array detection. Phytochem. Anal. 1996, 7, 305-312.

(18) Saulnier, L.; Crepeau, M. J.; Lahaye, M.; Thibault, J. F.; GarciaConesa, M. T.; Kroon, P. A.; Williamson, G. Isolation and structural determination of two 5,5'-diferuloyl oligosaccharides indicate that maize heteroxylans are covalently cross-linked by oxidatively coupled ferulates. Carbohydr. Res. 1999, 320, 82-92.

(19) Allerdings, E.; Ralph, J.; Schatz, P.; Gniechwitz, D.; Steinhart, H.; Bunzel, M. Isolation and structural identification of diarabinosyl 8-O-4-dehydrodiferulate from maize bran insoluble fibre. Phytochemistry 2005, 66, 113-124.

(20) Hatfield, R. D.; Ralph, J. Modeling the feasibility of intramolecular dehydrodiferulate formation in grass walls. J. Sci. Food Agric. 1999, 79, 425-427.

(21) Helm, R. F.; Ralph, J. Stereospecificity for zinc borohydride reduction of $\alpha$-aryloxy- $\beta$-hydroxy ketones. J. Wood Chem. Technol. 1993, 13, 593-601.

(22) Morreel, K.; Ralph, J.; Kim, H.; Lu, F.; Goeminne, G.; Ralph, S. A.; Messens, E.; Boerjan, W. Profiling of oligolignols reveals monolignol coupling conditions in lignifying poplar xylem. Plant Physiol. 2004, 136, 3537-3549.

(23) Morreel, K.; Kim, H.; Lu, F.; Dima, O.; Akiyama, T.; Vanholme, R.; Niculaes, C.; Goeminne, G.; Inzé, D.; Messens, E.; Ralph, J.; Boerjan, W. Mass-spectrometry-based fragmentation as an identification tool in lignomics. Anal. Chem. 2010, 82, 8095-8105.

(24) Bunzel, M.; Ralph, J.; Marita, J. M.; Hatfield, R. D.; Steinhart, $\mathrm{H}$. Diferulates as structural components in soluble and insoluble dietary fibre. J. Sci. Food Agric. 2001, 81, 653-660.

(25) Grabber, J. H.; Ralph, J.; Hatfield, R. D. Model studies of ferulate-coniferyl alcohol cross-product formation in primary maize walls: implications for lignification in grasses. J. Agric. Food Chem. 2002, 50, 6008-6016.

(26) Bunzel, M.; Ralph, J.; Lu, F.; Hatfield, R. D.; Steinhart, H. Lignins and ferulate-coniferyl alcohol cross-coupling products in cereal grains. J. Agric. Food Chem. 2004, 52, 6496-6502.

(27) Waterstraat, M.; Bunzel, D.; Bunzel, M. Identification of 8-O-4/ 8-5(cyclic)- and 8-8(cyclic)/5-5-coupled dehydrotriferulic acids, naturally occurring in cell walls of mono- and dicotyledonous plants. J. Agric. Food Chem. 2016, 64, 7244-7250.

(28) Schäfer, J.; Urbat, F.; Rund, K.; Bunzel, M. A stable-isotope dilution GC-MS approach for the analysis of DFRC (derivatization followed by reductive cleavage) monomers from low-lignin plant materials. J. Agric. Food Chem. 2015, 63, 2668-2673.

(29) Regner, M.; Bartuce, A.; Padmakshan, D.; Ralph, J.; Karlen, S. D. Reductive cleavage method for quantitation of monolignols and low-abundance monolignol conjugates. ChemSusChem 2018, 11, $1600-1605$.
(30) Iiyama, K.; Lam, T. B. T.; Stone, B. A. Phenolic acid bridges between polysaccharides and lignin in wheat internodes. Phytochemistry 1990, 29, 733-737.

(31) Grabber, J. H.; Hatfield, R. D.; Ralph, J.; Zon, J.; Amrhein, N. Ferulate cross-linking in cell walls isolated from maize cell suspensions. Phytochemistry 1995, 40, 1077-1082.

(32) Lundquist, K., Acidolysis. In Methods in lignin chemistry; Lin, S. Y., Dence, C. W., Eds.; Springer-Verlag: Berlin, 1992; pp 289-300.

(33) Dobberstein, D.; Bunzel, M. Identification of ferulate oligomers from corn stover. J. Sci. Food Agric. 2010, 90, 1802-1810.

(34) Bunzel, M.; Ralph, J.; Brüning, P.; Steinhart, H. Structural identification of dehydrotriferulic and dehydrotetraferulic acids isolated from insoluble maize fiber. J. Agric. Food Chem. 2006, 54, 6409-6418. 

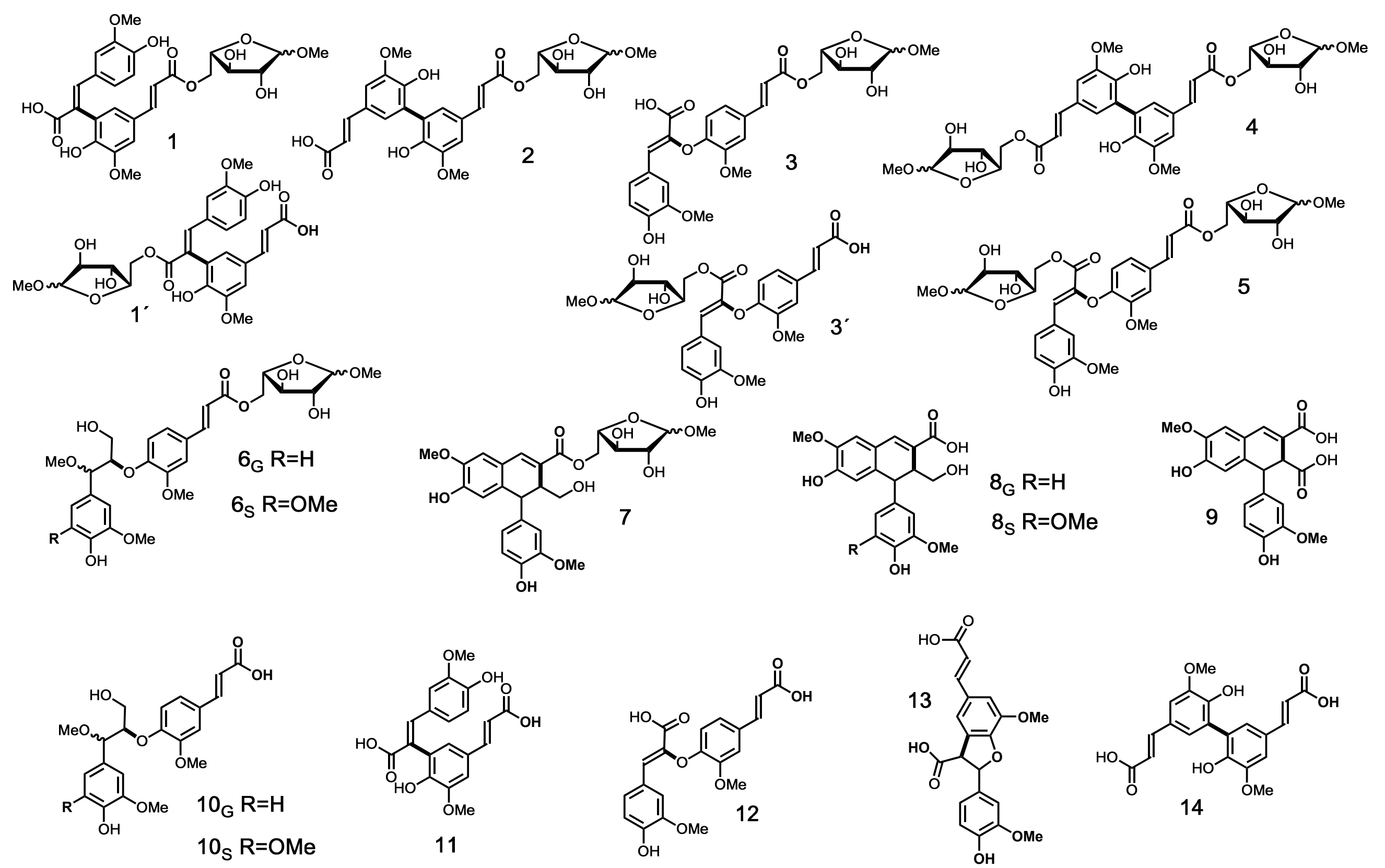

Figure S1. Main arabinose diphenolic conjugates released by mild acidolysis of grass samples (compounds 1 to 7 ) and their corresponding aglycones (compounds 8 to 14) obtained by mild alkaline hydrolysis of the acidolysis sample. 


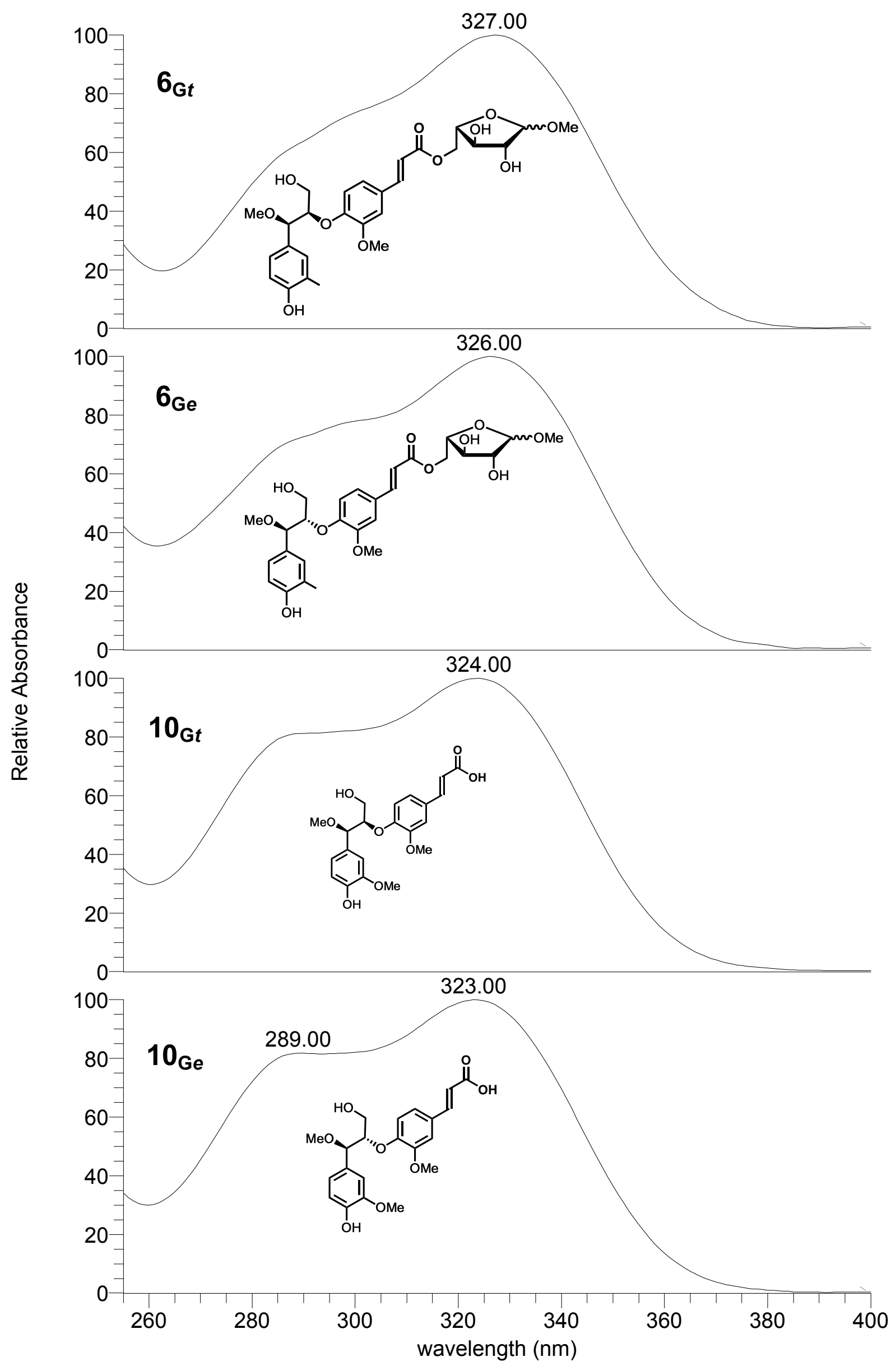

Figure S2. UV spectra of MeG-( $\beta$ - O-4)-FA-MeAra threo and erythro isomers $\left(\mathbf{6}_{\mathbf{G} t}\right.$ and $\mathbf{6}_{\mathbf{G e}}, \beta$ - or $\alpha$-anomer) and of their corresponding aglycones $\left(\mathbf{1 0}_{\mathrm{Gt}}\right.$ and $\left.\mathbf{1 0}_{\mathrm{Ge}}\right)$ 

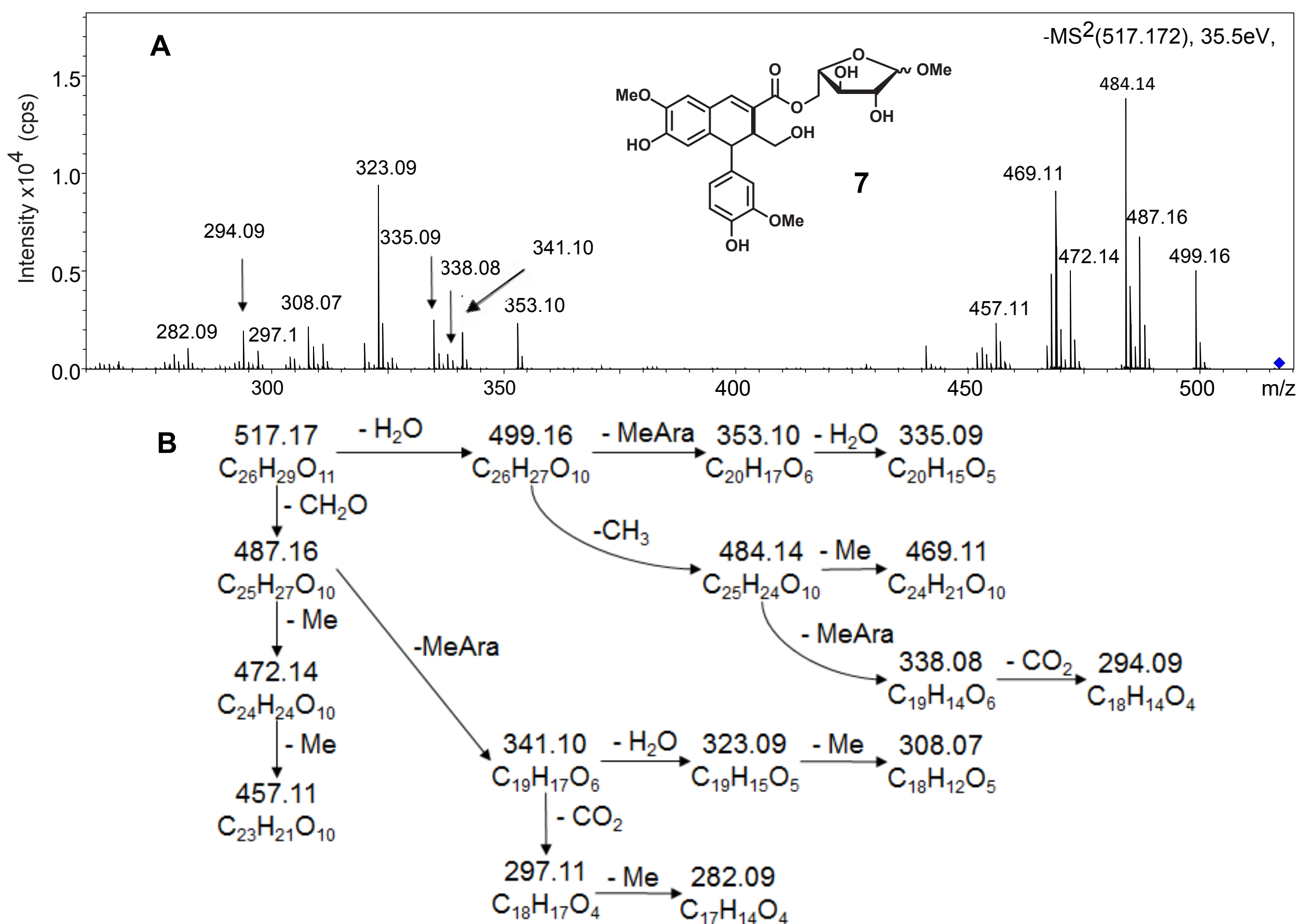

Figure S3. A) MS ${ }^{2}$ spectra (ESI, negative-ion mode, ion 517.172 fragmented at collision energy of $35.5 \mathrm{eV}$ ) of the G-( $\left.\beta-8 \mathrm{c}\right)$-FA-MeAra isomers 7 recovered after acidolysis from miscanthus internode. These isomers occur as a mixture of $\beta$ - and $\alpha$ - anomers provided with similar MS ${ }^{2}$ spectra. B) Corresponding fragmentation scheme. Vertical axis scale in cps, counts per second. 

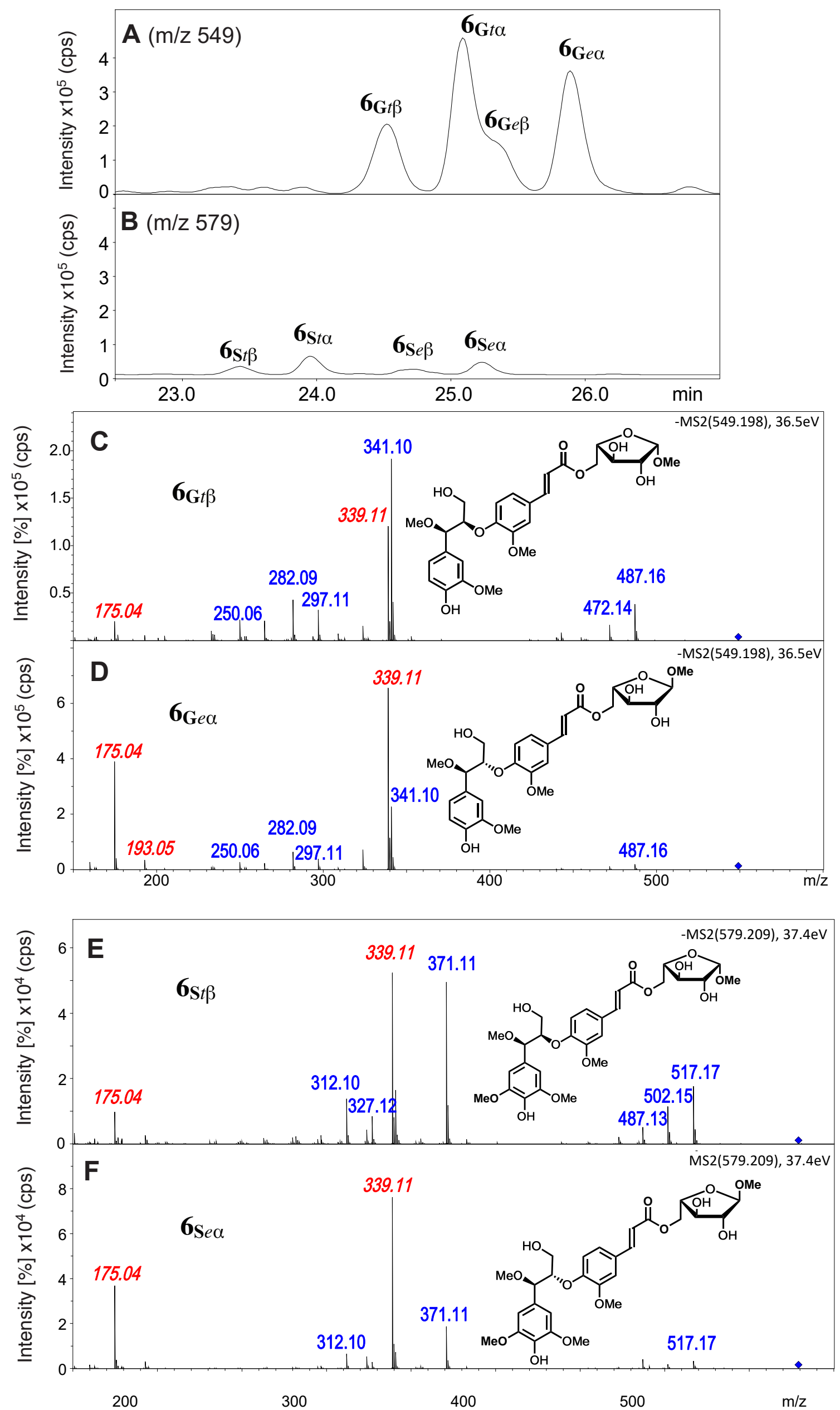

Figure S4. LC-MS analysis of the MeG-( $\beta-\mathrm{O}-4)-\mathrm{FA}-\mathrm{MeAra} \mathbf{6}_{\mathrm{G}}$ and MeS-( $\left.\beta-\mathrm{O}-4\right)-\mathrm{FA}-\mathrm{MeAra} \mathbf{6}_{\mathrm{S}}$ conjugates recovered by acidolysis of miscanthus sample. Each conjugate occurs as four resolved peaks corresponding to the threo and erythro forms of the $\beta$ - and $\alpha$ - anomers. The two partial chromatograms are reconstructed at A) $\mathrm{m} / \mathrm{z} 549$ and B) $\mathrm{m} / \mathrm{z} 579$ and are shown with the same intensity scale. The MS ${ }^{2}$ spectra corresponding to peaks $\mathbf{6}_{\mathrm{Gt \beta}}, \boldsymbol{6}_{\mathrm{Ge \alpha}}, \mathbf{6}_{\mathrm{St} \beta}$ and $\mathbf{6}_{\text {sea }}$ are shown in $\mathrm{C}, \mathrm{D}, \mathrm{E}$ and $\mathrm{F}$ respectively. Fragment ions from ( $\beta-\mathrm{O}-4)$ cleavage are in red while those form vinyl ether formation are in blue (relative intensity higher for the threo isomers).Vertical axis scales in cps, counts per second. 


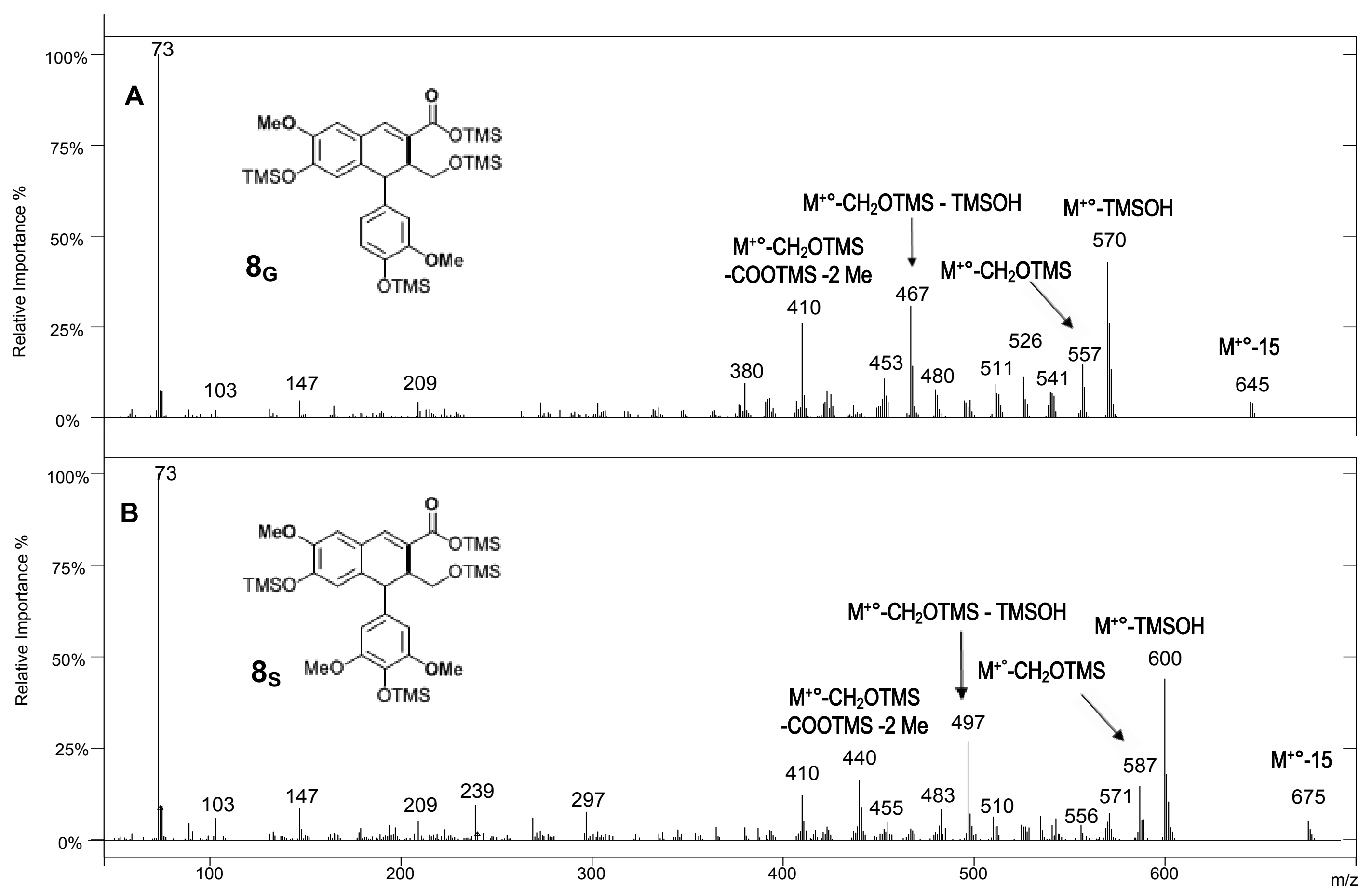

Figure 55. Mass spectra (electron impact, $70 \mathrm{eV}$ ) of $\mathrm{G}-(\beta-8 \mathrm{c})-\mathrm{FA} \mathbf{8}_{\mathbf{G}}$ and $\mathrm{S}-(\beta-8 \mathrm{c})-\mathrm{FA} \mathbf{8}_{\mathbf{S}}$ dimers (analyzed by GC-MS of their TMS derivatives). The molecular ions at $\mathrm{m} / \mathrm{z} 660$ and 690 are not detected.The 1,3-elimination of TMSOH (-90 Da) is characteristic of 3-aryl-1-propanol sidechains. 


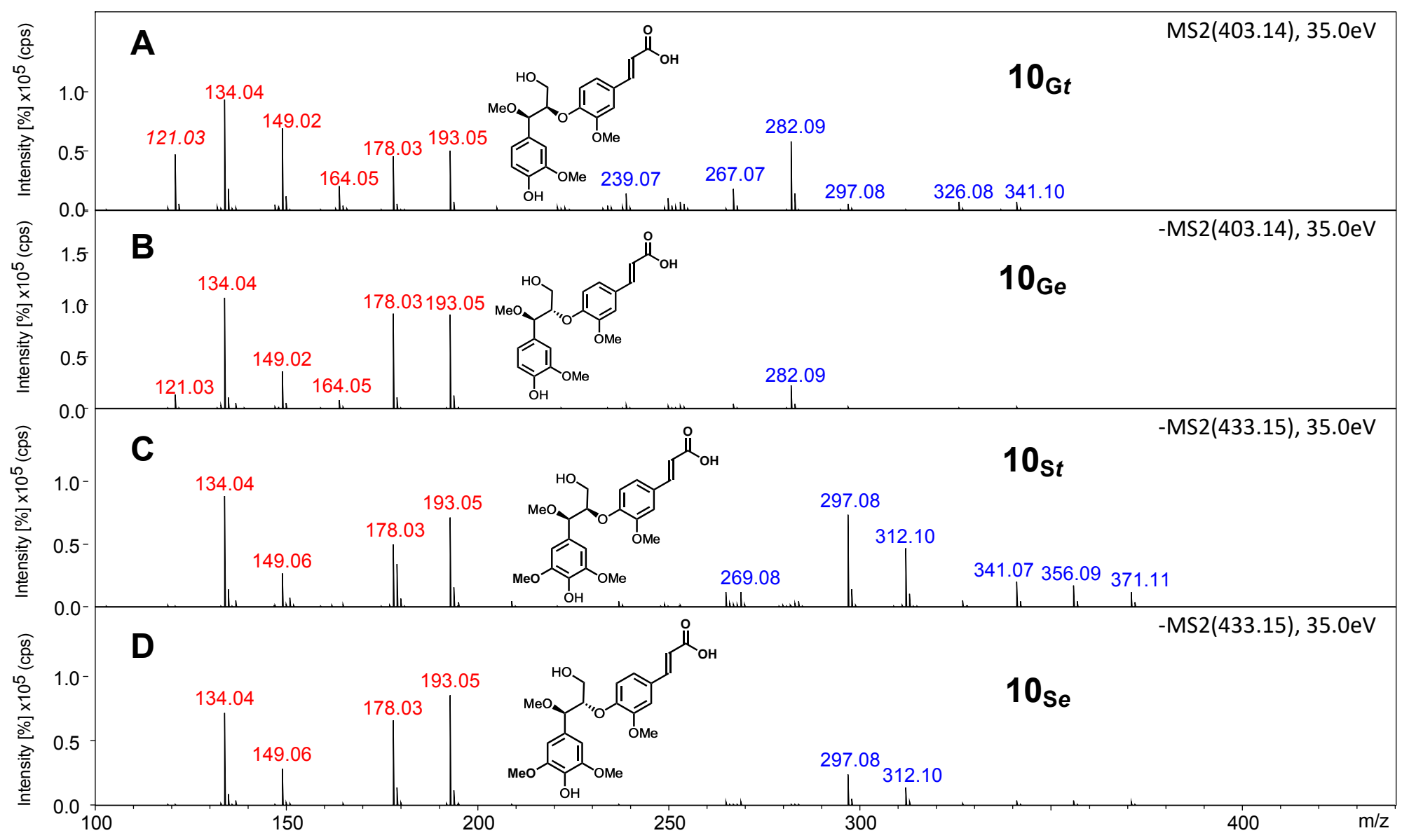

E

a) Ether cleavage<smiles>CCC(C)[C@H](O)[C@H](CO)Oc1ccc(/C=C/C(=O)O)cc1</smiles>

b) Vinyl ether formation
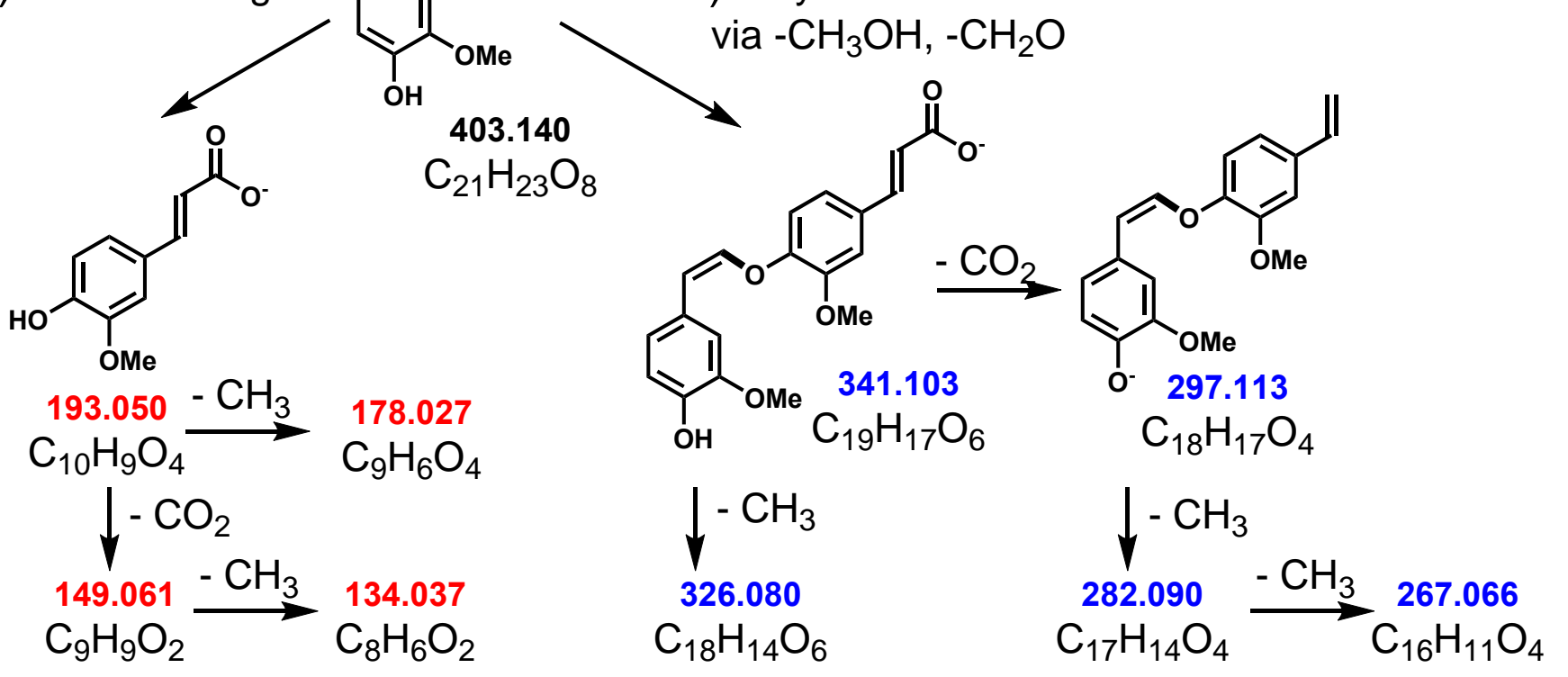

Figure S6. MS ${ }^{2}$ (negative-ion mode) of the A) $\left.\left.10 \mathrm{Gt}, \mathrm{B}\right) 10 \mathrm{Ge}, \mathrm{C}\right) 10 \mathrm{St}$ and D) $10 \mathrm{Se}$ threo (t) and erythro (e) isomers obtained by alkaline hydrolysis of miscanthus acidolysis mixture. The corresponding fragmentation pathway is shown in $\mathrm{E}$ for the $10 \mathrm{G}$ isomers. Ions in red are issued from pathway a (ether cleavage) and ions in blue from pathway $b$ (vinyl ether formation). lons from pathway $b$ are relatively more intense for the threo isomers. Vertical axis scales in cps, counts per second. 

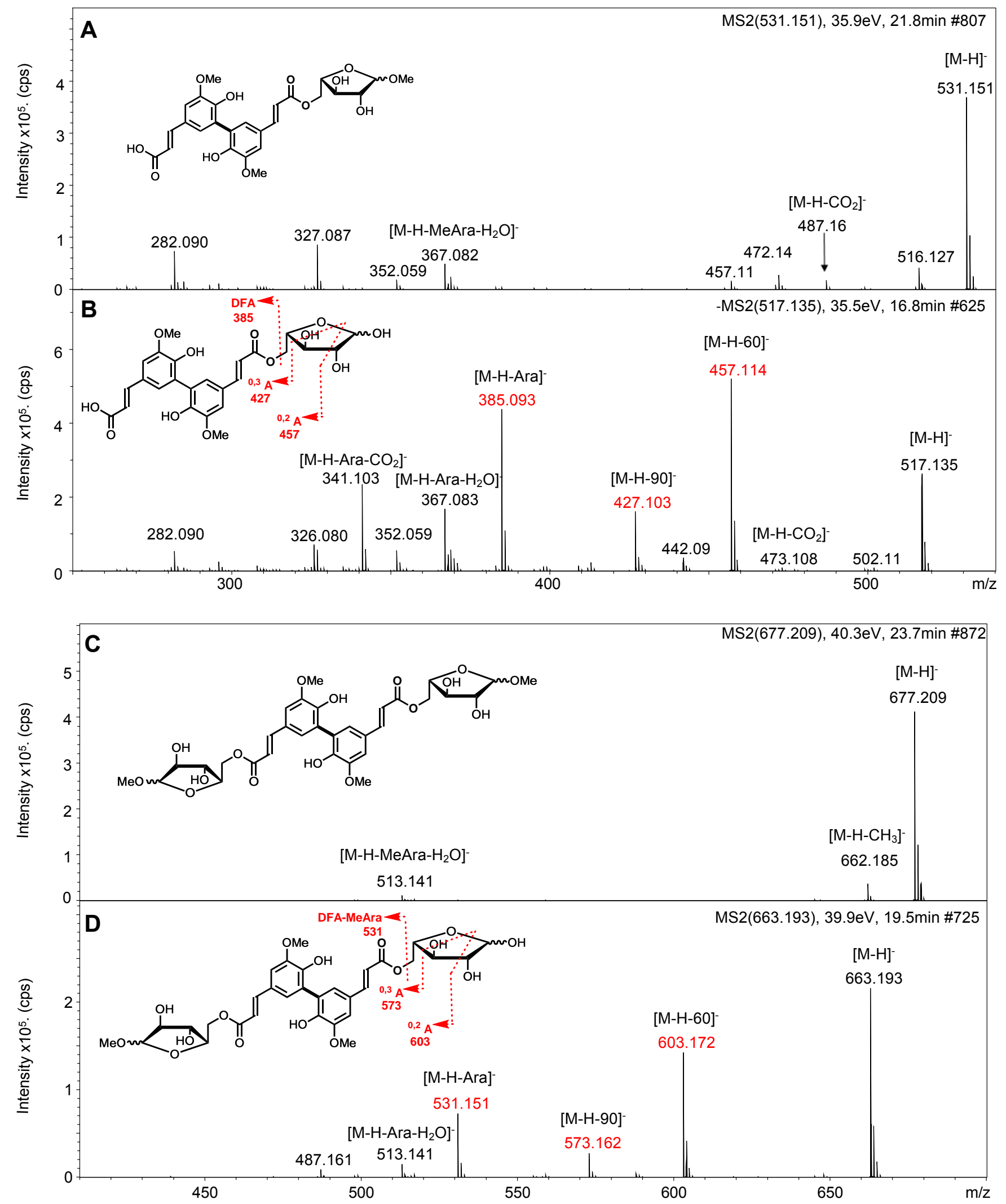

Figure S7. Comparative MS $^{2}$ spectra (negative-ion mode) of A) FA-(5-5)-FA-MeAra, B) FA-(5-5)-FA-Ara, C) FA-MeAra-(5-5)-FA-MeAra and D) FA-MeAra-(5-5)-FA-Ara. When one arabinofuranose ring is not methylated at $\mathrm{O}-1$ (in $\mathrm{B}$ and $\mathrm{D}$ ), fragment ions issued from the cross-ring cleavage of the arabinofuranose ring are substantially observed $\left([\mathrm{M}-\mathrm{H}-60]^{-}\right.$and $\left.[\mathrm{M}-\mathrm{H}-90]^{-}\right)$as well as the $\left([\mathrm{M}-\mathrm{H}-\text { Ara }]^{-}\right.$ion. By contrast, these ions are not observed when the arabinofuranose ring is methylated at $\mathrm{O}-1$ (in $\mathrm{A}$ and $\mathrm{C}$ ); the tiny ion at $\mathrm{m} / \mathrm{z}$ 457.11 in A) may be assigned to $\left.\left[\mathrm{M}-\mathrm{H}-\mathrm{CO}_{2}-2 \times \mathrm{CH}_{3}\right]^{-}\right)$. This result suggests that methylation at $\mathrm{O}-1$ of the arabinofuranose ring prevents the cross-ring cleavages of the sugar ring. Vertical axis scales in cps, counts per second. 
Table S1. Relative surface ratio of the MeS-( $\beta-O-4)-F A-M e A r a$ anomers to the MeG-( $\beta-O-4)-$ FA-MeAra anomers released by acidolysis of extract-free miscanthus or maize lignified samples. This ratio is calculated from chromatograms reconstructed at m/z 579 and 549 , respectively.

\begin{tabular}{ll}
\hline \multicolumn{1}{c}{ Sample } & Surface ratio \\
& MeS- $(\beta-O-4)-F A-M e A r a / M e G-(\beta-O-4)-F A-M e A r a$ \\
Lower internode from & $0.088(0.006)$ \\
M. sinensis & $0.089(0.007)$ \\
\hline Maize stem (silage stage) & \\
F2 INRA line &
\end{tabular}

The data correspond to mean values (SD) between triplicate analyses 